\title{
Circuit Formation and Function in the Olfactory Bulb of Mice with Reduced Spontaneous Afferent Activity
}

\author{
Paolo Lorenzon, ${ }^{1 \star}$ Nelly Redolfi, ${ }^{1 \star}$ Michael J. Podolsky, ${ }^{2}$ Ilaria Zamparo, ${ }^{1}$ Sira Angela Franchi, ${ }^{1}$ Gianluca Pietra, ${ }^{3}$ \\ Anna Boccaccio, ${ }^{4}$ Anna Menini, ${ }^{3}$ Venkatesh N. Murthy, ${ }^{5}$ and Claudia Lodovichi ${ }^{1,6}$ \\ ${ }^{1}$ Venetian Institute of Molecular Medicine (VIMM), 35129 Padua, Italy, ${ }^{2}$ Department of Medicine, Massachusetts General Hospital, Boston, Massachusetts \\ 02114, ${ }^{3}$ Neurobiology Group, SISSA, International School for Advanced Studies, 34136 Trieste, Italy, ${ }^{4}$ Biophysics Institute, CNR, 16149 Genova, Italy, \\ ${ }^{5}$ Department of Molecular and Cellular Biology and Center for Brain Science, Harvard University, Cambridge, Massachusetts 02138, and ${ }^{6} \mathrm{Neuroscience}$ \\ Institute, CNR, 35129 Padua, Italy
}

The type of neuronal activity required for circuit development is a matter of significant debate. We addressed this issue by analyzing the topographic organization of the olfactory bulb in transgenic mice engineered to have very little afferent spontaneous activity due to the overexpression of the inwardly rectifying potassium channel Kir2.1 in the olfactory sensory neurons (Kir2.1 mice). In these conditions, the topography of the olfactory bulb was unrefined. Odor-evoked responses were readily recorded in glomeruli with reduced spontaneous afferent activity, although the functional maps were coarser than in controls and contributed to altered olfactory discrimination behavior. In addition, overexpression of Kir2.1 in adults induced a regression of the already refined connectivity to an immature (i.e., coarser) status. Our data suggest that spontaneous activity plays a critical role not only in the development but also in the maintenance of the topography of the olfactory bulb and in sensory information processing.

Key words: behavior; functional imaging; olfactory bulb; olfactory system; sensory map; topography

\section{Introduction}

Specificity of connectivity in the CNS is essential for normal brain function. In sensory systems, peripheral neurons project axons to precise loci in the brain to generate topographic maps that define the quality and the location of environmental stimuli. In the olfactory bulb $(\mathrm{OB})$ a sensory map is generated by the convergence of olfactory sensory neurons (OSNs) expressing the same odorant receptor (OR) to form glomeruli (homogeneous glomeruli) in specific loci on the medial and on the lateral side of each OB (Ressler et al., 1994; Vassar et al., 1994; Mombaerts, 1996).

A glomerulus defines a functional unit, i.e., an odor column, consisting of the tufted and the mitral cells, receiving inputs from a specific group of sensory neurons, along with the granule cells connected to them (Shepherd, 2004). A second level of topographic organization is provided by the intrabulbar associational system (Schoenfeld et al., 1985), which connects specifically and reciprocally homologous glomeruli (Belluscio et al., 2002; Lodovichi et al., 2003; i.e., homologous odor columns).

\footnotetext{
Received Feb. 12, 2014; revised 0ct. 15, 2014; accepted Nov. 4, 2014.

Author contributions: C.L. designed research;P.L., N.R., M.J.P., I.Z., S.A.F., and G.P. performed research;P.L., N.R., M.J.P., I.Z., S.A.F., G.P., A.B., A.M., V.N.M., and C.L. analyzed data; A.B., A.M., V.N.M., and C.L. wrote the paper.

This work was supported by an Armenise-Harvard Career Developmental Award and by the Cariparo Grant to C.L. We are grateful to J.A. Gogos for generously providing the P2-IRES-GFP and the tet ${ }_{0}$-Kir2.1-IRES-tauLacZ mice. We thank Luca Dall'Arche for helping with behavioral experiments.

*P.L. and N.R. contributed equally to this work.

The authors declare no competing financial interests.

Correspondence should be addressed to Claudia Lodovichi, Neuroscience Institute-CNR and VIMM, Via Orus 2-35129 Padova, Italy. E-mail: claudia.lodovichi@unipd.it.

DOI:10.1523/JNEUROSCI.0613-14.2015

Copyright $\odot 2015$ the authors $\quad 0270-6474 / 15 / 350146-15 \$ 15.00 / 0$
}

The development of sensory maps is regulated by the complex interaction between spatially and temporally regulated axon guidance molecules and neuronal activity (Huberman et al., 2008; Feldheim and O'Leary, 2010). Spontaneous and sensory-evoked activity play important roles in the formation of sensory circuits (Zhang and Poo, 2001). The exact contribution provided by each type of activity remains, however, largely to be understood.

The topographic organization of the $\mathrm{OB}$ hinges on the $\mathrm{OR}$ identity that defines the organization of homogeneous glomeruli and of the related odor columns (Sakano, 2010; Murthy, 2011). Odor-evoked activity does not affect significantly the organization of the sensory map (Belluscio et al., 1998; Lin et al., 2000; C. Zheng et al., 2000), although it perturbs the intrabulbar projections (Marks et al., 2006). However, spontaneous activity may play a role. OSNs exhibit spontaneous firing (Hallem and Carlson, 2004; Reisert, 2010) that could originate from the spontaneous activity of the odorant receptor (Connelly et al., 2013). Spontaneous firing in the OSNs has been shown to be required for the formation of the sensory map (Yu et al., 2004). Whether the spontaneous firing of OSNs can modulate the whole topographic organization of the $\mathrm{OB}$, namely the organization of glomeruli, their intrabulbar connections and the related functional maps, remains unknown.

To address these critical issues, we took advantage of a line of mice genetically modified to have very little afferent spontaneous activity due to the overexpression of the inwardly rectifying potassium channel Kir2.1 in the OSNs (Yu et al., 2004). Using a combination of anatomical tracing, functional imaging, and behavioral analysis, we found that the olfactory bulb of Kir2.1 mice 
exhibited unrefined connectivity that in turn could contribute to the altered olfactory information processing and olfactory behavior. In addition, we found that overexpression of Kir2.1 in adults induces a regression of the already mature neural circuits. These data suggest that spontaneous afferent activity is required for the development and for the maintenance of neural circuits in the olfactory bulb.

\section{Materials and Methods}

All animal procedures were performed under a protocol approved by the ethic committee of the University of Padua, of the University of Trieste, and the institutional guidelines of Harvard University.

Mutant mouse lines. Experiments were performed on the following genetically modified lines of mice: OMP-IRES-tTA/Tet ${ }_{\mathrm{o}}$ (RRDI: MGI: 3721403)-Kir2.1-IRES-tau-LacZ (Kir2.1, RRDI: MGI:3723462), P2-IRESGFP (P2-GFP), and M71-IRES-GFP (M71-GFP, RRDI: IMSR_JAX:

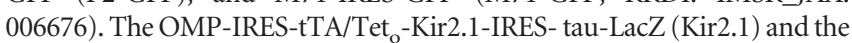
P2-IRES-GFP (P2-GFP), generously provided by J.A. Gogos (Columbia University, New York, NY), were described in detail previously (Gogos et al., 2000; Yu et al., 2004). The M71-IRES-GFP (M71-GFP) mice, described in detail previously (Feinstein et al., 2004), were purchased from the The Jackson Laboratory.

$\mathrm{Ca}^{2+}$ imaging. Procedures were modified from those in Maritan et al., 2009. Briefly, the olfactory epithelium was harvested from P25-P30 control and Kir2.1 mice in ice-cold HBSS (Invitrogen). Tissue was enzymatically dissociated and the resultant cell suspension was plated on $24 \mathrm{~mm}$ coverslip coated with poly-L-lysine (Sigma) and maintained in culture medium [D-Val Mem; 10\% FBS, 5\% Nu Serum, Penstrep L-glutamine, $100 \mathrm{U} / \mathrm{ml}$ (Invitrogen), $10 \mu \mathrm{M}$ Ara-C (Sigma), and $25 \mathrm{ng} / \mathrm{ml} \mathrm{NGF} \mathrm{(BD}$ Biosciences) under standard conditions for 1-2 h (Ronnett et al., 1991). Neurons were then loaded with $8 \mu \mathrm{M}$ fura-2 AM, $80 \mu \mathrm{g} / \mathrm{ml}$ Pluronic $\mathrm{F} 127$, and $250 \mu \mathrm{M}$ sulfinpyrazone (Invitrogen) at $37^{\circ} \mathrm{C}$ for $30-40 \mathrm{~min}$. Dissociated preparations were constantly perfused $(3 \mathrm{ml} / \mathrm{min})$ except during stimulus presentation (4-10 s, bath applied).

The odorant stimuli were represented by mixtures of several compounds including: citralva, citronellal, menthone, carvone, eugenol, geraniol, acethophenone, hexanal, benzyl alcohol, heptanoic acid, propionic acid, benzaldehyde, and IBMP (all from Sigma) prepared as 1 mM stock in Ringer's solution and diluted to the final concentration of 1 $\mu \mathrm{M}$ and 10 and $200 \mu \mathrm{M}$ for each odorant in the bath. This stimulus concentration is well within the range ( $1 \mathrm{~nm}$ to $1 \mathrm{~mm}$ ) of those used in previous imaging (Bozza and Kauer, 1998; Maritan et al., 2009; Pietrobon et al., 2011) and electrophysiological studies (Reisert, 2010, Connelly et al., 2013, Tan et al., 2010) on OSNs.

$\mathrm{Ca}^{2+}$ imaging experiments were performed on an inverted microscope (Olympus IX 81 with a $40 \times$ NA 1.3 oil-immersion objective). The microscope was equipped with a CCD camera (SIS-F View) and an illumination system (MT 20; Olympus). Images were acquired every $3 \mathrm{~s}$ using Cell software using 380/15 and 340/15 nm excitation filters and a $510 / 40 \mathrm{~nm}$ emission filter. Images were processed off-line using ImageJ software $(\mathrm{NIH})$. Changes in fluorescence $(340 \mathrm{~nm} / 380 \mathrm{~nm})$ were expressed as $R / R_{0}$, where $R$ is the ratio $(340 \mathrm{~nm} / 380 \mathrm{~nm})$ at time $t$ and $R_{0}$ is the ratio at time $=0 \mathrm{~s}$. Response amplitude (\%) was evaluated as $\Delta R / R_{0}$ $\times 100$, where $\Delta R=R-R_{0}$. The duration of the calcium response was calculated as the time (s) between the onset of the calcium rise and the return to baseline of the calcium signal.

Electrophysiology. Kir2.1 and wild-type control mice (4-8 weeks) were anesthetized with $\mathrm{CO}_{2}$ inhalation and decapitated and the head was immediately put in ice-cold ACSF bubbled with $95 \% \mathrm{O}_{2}$ and $5 \% \mathrm{CO}_{2}$. ACSF contained the following (in mM): $120 \mathrm{NaCl}, 5 \mathrm{KCl}, 1 \mathrm{MgSO}_{4}, 1 \mathrm{CaCl}_{2}, 25$ $\mathrm{NaHCO}_{3}, 10$ glucose, and 10 HEPES, pH 7.2. The nasal septum was dissected en bloc and the tissue was placed in a recording chamber continually perfused by bubbled ACSF. Dendritic knobs of OSNs present in the main olfactory epithelium were viewed using an upright microscope (Olympus BX51WI) by infrared differential contrast optics with a $40 \times$ water-immersion objective and a $2 \times$ lens.

Extracellular recordings from dendritic knobs of OSNs were obtained in the loose-patch configuration with seal resistances of 20-40 M $\Omega$
(Nunemaker et al., 2003; Delay and Restrepo, 2004). The pipette solution was the same as the bath solution. Patch pipettes, pulled from borosilicate capillaries (WPI) with a Narishige PC-10 puller, had a resistance of $\sim 5-10 \mathrm{M} \Omega$. Recordings were made in voltage-clamp mode with a holding potential of $0 \mathrm{mV}$ using a Multiclamp 700B amplifier controlled by Clampex 9.2 via a Digidata 1322A (Molecular Devices). Data were lowpass filtered at $1 \mathrm{kHz}$ and sampled at $5 \mathrm{kHz}$. Experiments were performed at room temperature $\left(20-25^{\circ} \mathrm{C}\right)$.

The odorant mixture had the same compounds (each at $1 \mathrm{~mm}$ in ACSF solution) of the odor mixture used in the $\mathrm{Ca}^{2+}$ imaging experiments (see above). The odorant stimulus was delivered by pressure ejection (4-8 psi), 150 ms duration, using a Picospritzer II (Parker).

Spontaneous firing activity was defined as the mean firing frequency recorded in a time window of $2-5 \mathrm{~min}$. For spike detection raw data were filtered in the window of 5-700 Hz. Odor-evoked firing activity was detected on the spontaneous background activity using an established protocol for OSN response analysis (Rospars et al., 2003). Briefly, neuronal spiking activity was defined as a response to odor when, within $1.25 \mathrm{~s}$ after stimulus presentation, at least three consecutive spikes presented an instant frequency (IF; 1/interspike interval) higher than the mean instant frequency in the $30 \mathrm{~s}$ before stimulus presentation plus $1.5 \mathrm{~Hz}$ (IF $>$ avgIF $+1.5 \mathrm{~Hz}$ ). We defined saturating the responses consisting in an initial burst of firing activity, followed by a silent period, and by a firing rebound (Rospars et al., 2003; Savigner et al., 2009). The firing rate of the odor-evoked saturating responses was estimated as an interspike interval (ISI) of the first four spikes (Rospars et al., 2003).

Data from spontaneous firing frequency are presented as mean value \pm SEM and number of neurons $(n)$. Spontaneous firing frequency data were not normally distributed (Kolmogorov-Smirnov test) and statistical significance was determined using Mann-Whitney $U$ test. $P$ values $<0.05$ were considered statistically significant.

Optical imaging of intrinsic signal. Recordings of intrinsic optical signals from the olfactory bulb were made as reported previously (Rubin and Katz, 1999; Meister and Bonhoeffer, 2001; Soucy et al., 2009). Briefly, mice (P26-P30) were anesthetized lightly (ketamine/xylazine) and a window was made in the dorsal surface of the skull over the olfactory bulbs. The exposed tissue was covered with $1 \%$ agarose and a glass coverslip. Images were captured using a 35,000 electron/well CCD camera (CCD 1300-F; Vosskuhler) with a NIKON $55 \mathrm{~mm} \mathrm{f} / 2.8$ microlens (NI5528M) via an NI frame grabber board (NI PCI-1422). Two 60-LEDs chips (780 nm and 500mW; Roithner Laser Technik ) were attached to articulating arms (Edmund Optics) to illuminate the olfactory bulbs. Data acquisition software was developed in Igor (WaveMetrics) and LabView (National Instruments) by E. Soucy and A. Fantana (Soucy et al., 2009). A custom-built odor robot was used to deliver a large set of chemically diverse stimuli (97 compounds in mineral oil) presented at low concentrations $(\sim 0.1 \%$ saturated vapor pressure). Each stimulus was delivered for $30 \mathrm{~s}$ and preceded by $30 \mathrm{~s}$ of fresh air and the $97 \mathrm{stimuli}$ (and one fresh air control) were repeated three to five times. Images were captured at $25 \mathrm{~Hz}$. Frames taken during fresh air were averaged for the baseline fluorescence $(F)$ and frames taken during odor presentation were used for $\Delta F . \Delta F / F$ images of the entire field of view were generated and repeated trials of the same stimulus were averaged, yielding $98 \Delta F / F$ images, one for each of the stimuli and one for fresh air. Individual responding regions were selected and used for analysis. The size of the boxes used to demarcate responding regions was quantified as the radius of an ellipse circumscribed within the box. Thresholding for response amplitudes was determined as 1.5 SDs above threshold of the average light intensity change in each box for each odor. We used KolmogorovSmirnov tests as statistical tests of significance for distributions of statistics, reporting $p<0.05$ as significant.

In vivo tracer injections and imaging analysis. Tracer injections were performed and analyzed as described previously (Lodovichi et al., 2003).

Briefly, wild-type (C57BL/6), M71-GFP, and Kir2.1 mice were anesthetized with a mixture of Zoletil 100 (a combination of zolazepam and tiletamine, 1:1, $10 \mathrm{mg} / \mathrm{kg}$; Virbac) and Xilor (Xylazine 2\%, $0.06 \mathrm{ml} / \mathrm{kg}$; Bio98). The scalp was resected and the bone over the bulbs removed to provide access for tracer injections. Microinjections of tetramethylrhod- 

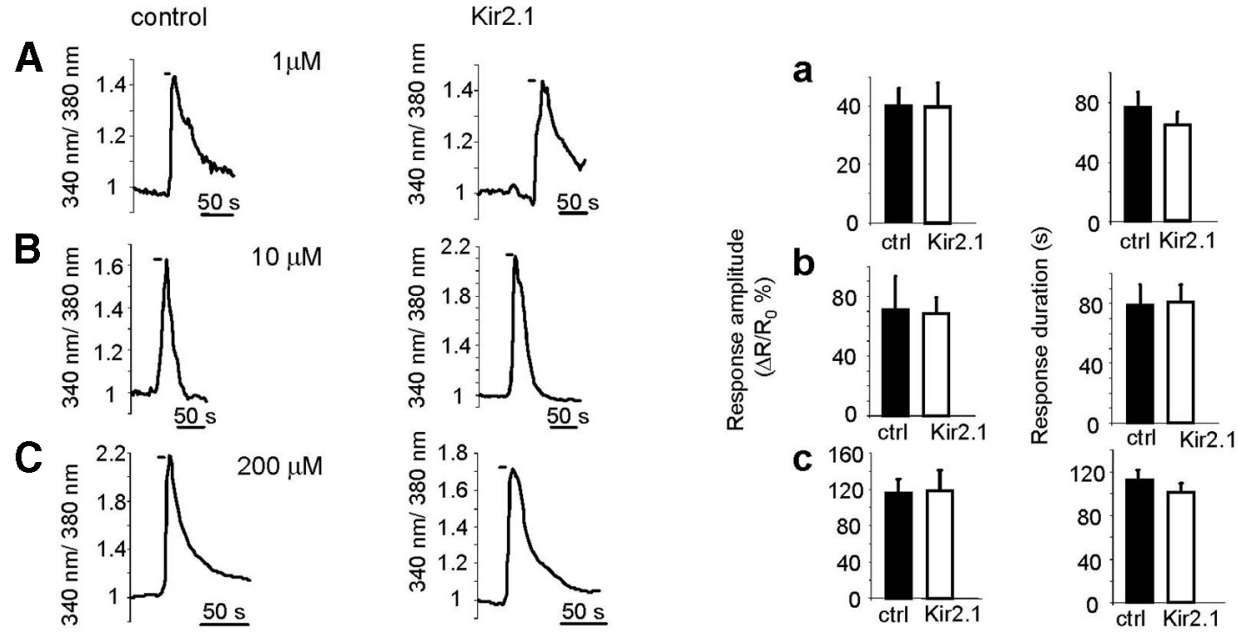
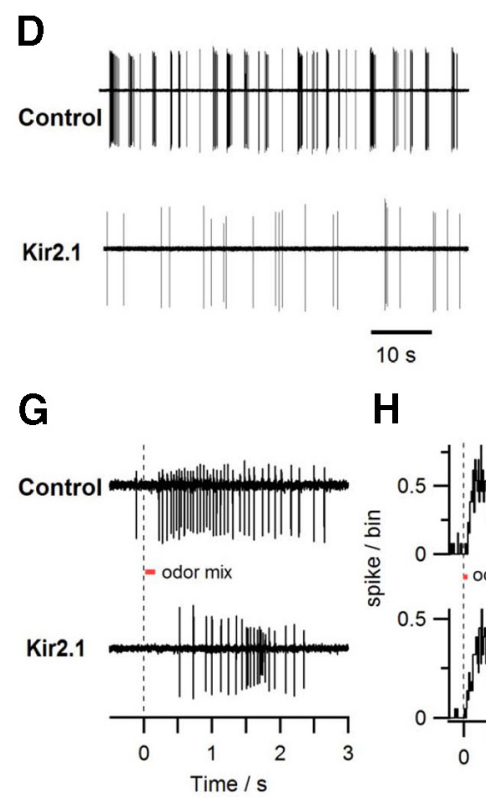

H
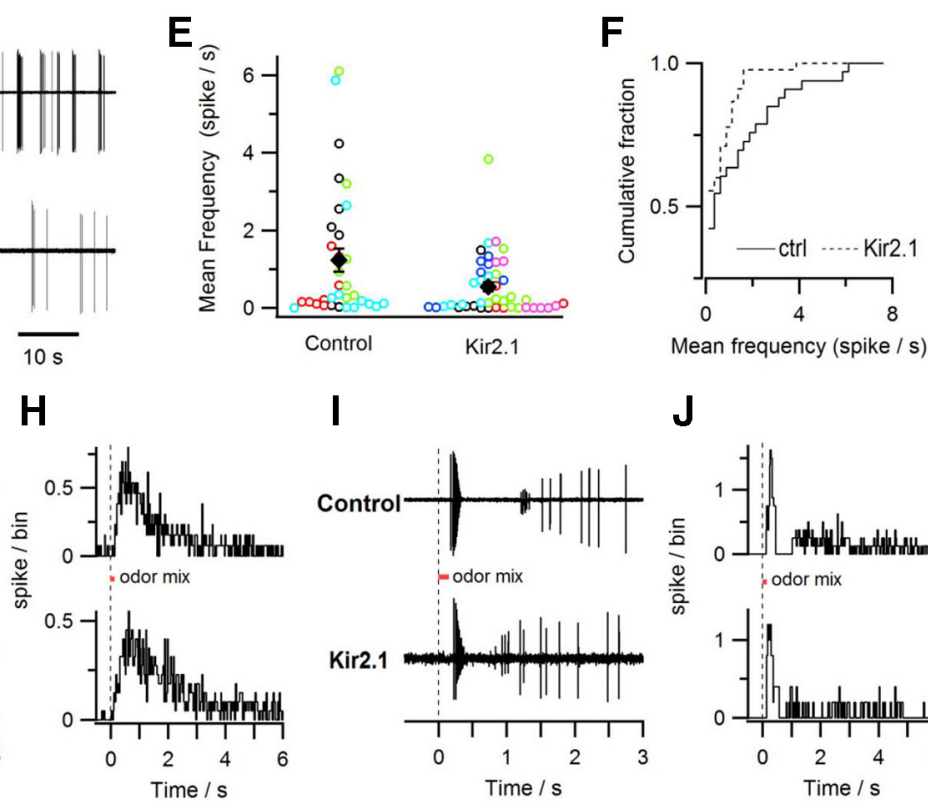

I

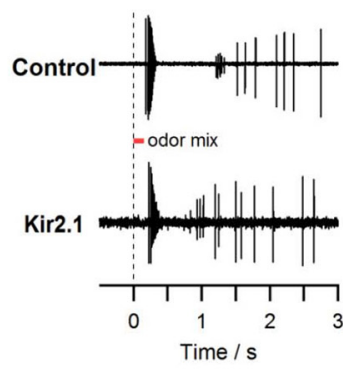

J
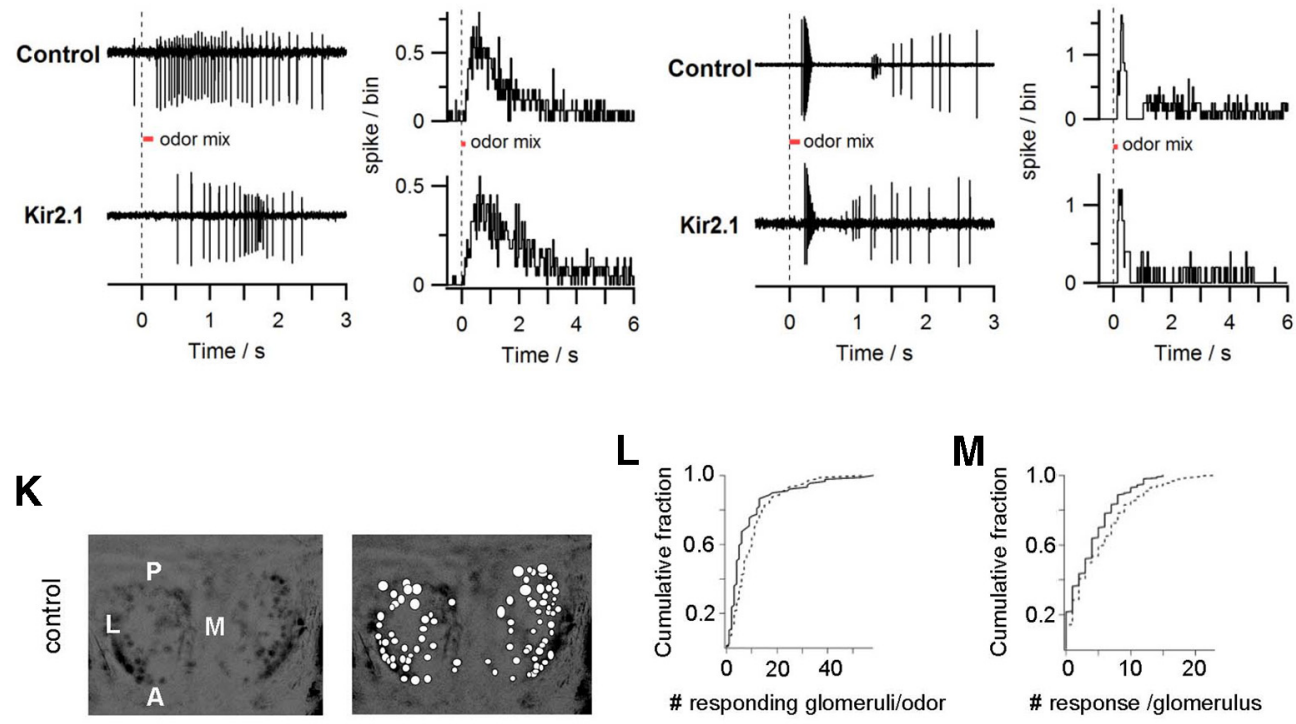

L
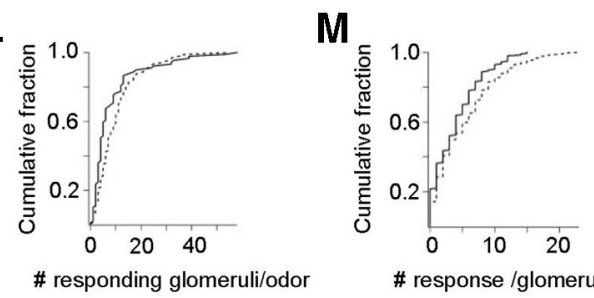

\# response /glomerulus
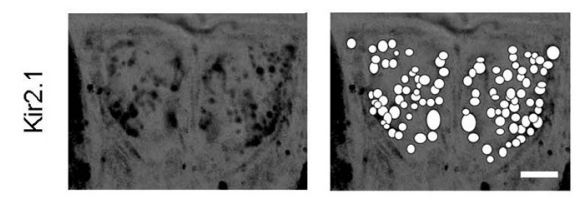
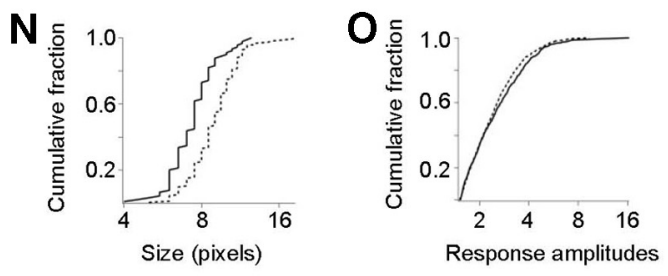

control

Kir2.1

Figure 1. Spontaneous and odor-evoked activity in OSNs in Kir2.1 mice. $\boldsymbol{A}-\boldsymbol{C}$, Normalized fluorescence ratio ( $340 \mathrm{~nm} / 380 \mathrm{~nm})$ changes in 0 SNs loaded with fura-2 and stimulated with a mixture of odors ( $\boldsymbol{A}, 1 \mu \mathrm{m} ; \boldsymbol{B}, 10 \mu \mathrm{m} ; \boldsymbol{C}, 200 \mu \mathrm{m})$ in control (left) and Kir2.1 (right) 0SNs. $\boldsymbol{a}-\boldsymbol{C}$, Amplitude of the calcium response $\left(\Delta R / R_{0} \%\right)$ and duration of the calcium response (s). Data are presented as mean \pm SEM. $\boldsymbol{D}$, Examples of traces of the spontaneous firing activity in OSNs, respectively, in control (top) and Kir2.1 mice (bottom). $\boldsymbol{E}$, Dispersion plot of spontaneous firing activity in 0SNs in control and Kir2.1 mice. Each symbol indicates a single OSN. OSNs from the same mouse are indicated with symbols of the same color. Black diamond, mean \pm SEM (Figure legend continues.) 
amine dextran, $3000 \mathrm{MW}$ (Invitrogen), were targeted to GFP-labeled glomeruli or to the glomerular layer, under an epifluorescent microscope (Leica MZ16). Tracer was iontophoresed $(+2 \mu \mathrm{A}, 50 \%$ duty cycle, $7 \mathrm{~s}$ pulses, for $2-3 \mathrm{~min}$ ) into the olfactory bulb through a glass micropipette (4-5 $\mu \mathrm{m}$ tip diameter). Eight to twelve hours after injections, mice were killed by a Xilor-Zoletil overdose and transcardially perfused with $0.9 \%$ saline, followed by $4 \%$ paraformaldehyde in $1 \times$ PBS. Olfactory bulbs were removed, post fixed overnight, sectioned (60 $\mu \mathrm{m}$ horizontal sections) at the vibratome (Leica; VT 1000S), and mounted (Aqua-Poly/ Mount; Polysciences).

In vitro tracer injections. P2-GFP and Kir2.1 $\times$ P2-GFP were deeply anesthetized with Xilor-Zoletil and decapitated. The bulbs were rapidly dissected in low $\mathrm{Ca}^{2+}$ ACSF (McQuiston and Katz, 2001) and bubbled with $95 \% \mathrm{O}_{2}$ and $5 \% \mathrm{CO}_{2}$. Under an epifluorescent microscope (Leica MZ16), targeted iontophoretic injections of tetramethylrhodamine dextran, 3000MW (Molecular Probes), were made in the medial P2-GFP glomerulus, using the same parameters used for the in vivo injections (above). Once injected, the bulbs were oxygenated in ACSF for 4-5 h, and then were fixed in $4 \%$ paraformaldehyde in $1 \times$ PBS and then processed as described above.

Confocal imaging acquisition and analysis. Sections were imaged on Leica SP5 confocal microscope with HC PL Fluotar 20×/0.50 NA objective (Leica). $Z$-stack series were collected in each section that contained any labeling related to the injection and the projection sites, respectively. The $Z$-stacks were then projected on the $X Y$ plane to obtain the maximum intensity projection, containing the entire reconstruction of the projection and of the injection sites, respectively.

Images were then analyzed using ImageJ software (NIH; RRID:nif0000-30467). To quantify the extent of the injection and the projection sites, images were processed as follows: (1) a threshold was created for each image by clicking in a nonlabeled area; (2) images were then background subtracted and converted in binary files, and an object with clearly defined border was obtained; and (3) the distance between the borders of this object was measured. The ratio between the projection and the injection site was calculated. Ratios for each experimental and control group were averaged and presented as mean $\pm \mathrm{SD}$.

Immunohistochemistry. Mice were killed with an Xilor-Zoletil overdose and transcardially perfused with $0.9 \%$ saline followed by $4 \%$ paraformaldehyde in $1 \times$ PBS. Olfactory bulbs were removed, post fixed overnight, and sectioned (60 $\mu \mathrm{m}$ horizontal sections) at the vibratome (Leica; VT 1000S). Sections were blocked with $0.5 \%$ Triton X-100 + 5\% normal donkey serum in $1 \times$ PBS for $60 \mathrm{~min}$. Sections were then reacted with primary antibody against OMP (1:500; Wako Chemicals catalog \#544-10001-WAKO RRID: AB_664696) at $4^{\circ} \mathrm{C}$ overnight. The primary antibody was visualized with $\mathrm{Cy} 3$-conjugated donkey anti-goat antibody (Jackson ImmunoResearch catalog \#705-165-147, RRID:

$\leftarrow$

(Figure legend continued.) $(1.23 \pm 0.29 \mathrm{~Hz}, n=33$ in control mice and $0.54 \pm 0.11 \mathrm{~Hz}, n=45$ in Kir2.1 mice). $\boldsymbol{F}$, Cumulative plot of spontaneous firing frequency, bin of $0.25 \mathrm{~Hz}$ (MannWhitney $U$ test, one-tail, $\left.{ }^{*} p=0.02\right)$. $G$, Representative recordings of nonsaturating responses to odors (150 ms) in control (top) and Kir2.1 0SNs (bottom). $\boldsymbol{H}$, Cumulative response to an odor puff ( $150 \mathrm{~ms}$ ) normalized to the number of neurons ( $n=13$ in control mice, $n=22$ in Kir2.1 mice; bin $30 \mathrm{~ms}$ ). $I$, Examples of saturating responses to odors (150 ms) in control (top) and Kir2.1 OSNs (bottom). J, Cumulative response to an odor puff (150 ms) normalized to the number of neurons ( $n=8$ in control mice, $n=5$ in Kir2.1 mice; bin $30 \mathrm{~ms}$ ). $\boldsymbol{K}$, Maximum intensity projection images of all odor responses collected in optical imaging of intrinsic signal experiments in glomeruli of the olfactory bulb of control (top) and in Kir2.1 mice (bottom). Darker regions indicate responding areas. Right, The responding spots are shown as white ellipses in control (top right) and in Kir2.1 mice (bottom right). Scale bar, $500 \mu \mathrm{m}$. M, medial; L, lateral; $A$, anterior; $P$, posterior. $L$, Cumulative distribution of the number of glomeruli activated by the same odorants. $\boldsymbol{M}$, Cumulative distribution of the number of responses recorded in each glomerulus. $N$, Cumulative distribution of the size of responding glomeruli upon odor stimulation. $\mathbf{0}$, Cumulative distribution of amplitude of the odor-evoked responses elicited in the glomeruli. Responses are shown as multiples of the SD of noise, with a threshold of 1.5 used to define a response. Cumulative fraction $=$ total number of events. Solid line, controls; dashed line, Kir2.1 mice.
AB_2307351) after $2 \mathrm{~h}$ incubation at room temperature. DAPI (Invitrogen) was used as nuclear counterstain. Images were acquired at the confocal microscope (Leica SP 5) using an HC PL Fluotar 20×/0.50 NA objective (Leica).

Mitral cell labeling. Mice heterozygous for tet $\mathrm{o}_{\mathrm{o}}$-Kir2.1-IRES-tauLacZ and wild-type C57BL/6 mice at P6-P8 were killed by decapitation. A small incision was made in the presumptive lateral olfactory tract and a small crystal of $\operatorname{DiI}_{18}$ (3) (Invitrogen) was applied. Brains were replaced in fixative and incubated at $37^{\circ} \mathrm{C}$ for $7-10 \mathrm{~d}$. Brains were then sectioned (60 $\mu \mathrm{m}$ sections) at the vibratome (Leica; VT 1000S). Sections were imaged at a Leica SP 5 confocal microscope with an HC PL Fluotar $20 \times / 0.50 \mathrm{NA}$ objective (Leica). $Z$-stacks through selected mitral cells were performed and projected on the $X Y$ plane to obtain the maximum intensity projections, containing the reconstruction of the entire cells.

Olfactory discrimination test. Wild-type control and Kir2.1 male mice, age $>\mathrm{P} 40$, were trained and tested to assess their ability to discriminate between pairs of odors: fenchone $(+)$ and $(-)$, carvone $(+)$ and $(-)$, 2-heptanol $(+)$ and (-), 2-methylbutyric acid (2MB), and cyclobutanecarboxylic acid $(\mathrm{cb})$, all from Sigma-Aldrich. For each pair of odors a group of $n=6$ control mice and a group of $n=6 \mathrm{Kir} 2.1$ mice was used. The behavioral paradigm was slightly modified from that used previously (Schellinck et al., 2001). Briefly, $4 \mathrm{~d}$ before training the animals were put on a food restriction schedule to maintain $80-85 \%$ of their free-feeding weight. Water was available ad libitum. Mice were trained for $4 \mathrm{~d}$ in the following way. Each mouse was exposed in $4 \times 10 \mathrm{~min}$ sessions to a conditional stimulus $(\mathrm{CS}+)$ contained in an odor pot hidden in the bedding of the cage, together with a piece of sugar $(0.05 \mathrm{~g})$. Each mouse was also exposed to the unconditioned stimulus (CS-) present in an odor pot hidden in the bedding of the cage, without the sugar. The CS+ and CS - were presented in different cages and each mouse was exposed randomly to $\mathrm{CS}+$ or to $\mathrm{CS}-$ during the course of the training day. Odor concentrations were as follows: $(+)$ carvone $(6.4 \mathrm{M}),(-)$ carvone $(6.4 \mathrm{M})$, $(-)$ fenchone $(6.2 \mathrm{M}),(+)$ fenchone $(6.2 \mathrm{M}),(-)$ 2-hepatonol (7.03 M), (+) 2-heptanol (7.01 M), 2-MB (9.1 M), cb acid (10.4 M). These odor concentrations are well within the range of those used in previous behavior experiments (Kobayakawa et al., 2007).

On the fifth day, mice were tested in a three-chamber apparatus. In the left and in the right compartment the CS + and CS - , in odor pots, were hidden in the bedding. Sugar was not present in the testing phase. The animal was introduced in the chamber apparatus, without odors, for 5 min for habituation. After that the odors were hidden in the lateral chambers and the animal introduced in the central chamber having free access to the side compartments of the apparatus. The ability of the mice to discriminate CS + versus CS - was assessed scoring the time spent investigating, digging, and sniffing around each odor pot, within a 2 min time window. The discrimination test was done blind to the conditioned odor. Differences between groups were evaluated using the Mann-Whitney test, ${ }^{*} p<0.05 ;{ }^{* *} 0.001<p<0.01$.

Modulation of Kir2.1 expression. To examine the effects of Kir2.1 expression only in adulthood, two experimental procedures were used. In the first one, animals were fed with doxycycline (Sigma-Aldrich; $6 \mathrm{mg} / \mathrm{g}$ pellet food) throughout gestation until P30 (to abolish Kir2.1 expression). At P30 the sensory map (i.e., organization of glomeruli; see above, Immunohistochemistry and main text) and the link between homologous glomeruli were studied. For the latter, focal tracer injections in vivo were performed as described above in Kir2.1 and control mice at P30. In the second experimental procedure, the doxycycline administration was suspended at P30 and the animals (Kir2.1 mice and controls) analyzed at P60. At P60, the sensory map and the link between homologous glomeruli were studied (see above). To assess the Kir2.1 expression, sections of the olfactory bulb of Kir2.1 and control animals at P30 and P60, respectively, were reacted with goat antibody specific for $\beta$-gal (1: 1000; MorphoSys catalog \#4600-1409, RRID: AB_2307350). The primary bound antibody was then visualized using anti-goat $\mathrm{Cy} 3$ conjugated (Jackson ImmunoResearch catalog \#705-165-147, RRID: AB_2307351). 


\section{Results}

Spontaneous and odor-evoked activity in OSNs overexpressing Kir2.1

The overexpression of Kir2.1 channel is supposed to dramatically reduce the spontaneous firing in OSNs ( $\mathrm{Yu}$ et al., 2004), although its effect on odor-evoked activity remained to be clarified. To address this point we analyzed the calcium dynamics in response to a mixture of odors in isolated OSNs loaded with the $\mathrm{Ca}^{2+}$ indicator fura-2. OSNs exhibited a fast onset, rapidly recovering $\mathrm{Ca}^{2+}$ signal in response to all the concentrations of odors tested $(1,10$, and $200 \mu \mathrm{M})$, which was not significantly different in Kir2.1 and in control mice ( $1 \mu \mathrm{M}$, controls: $n=$ 16, Kir2.1: $n=17$, amplitude of calcium response, $\Delta R / R_{0}(\%)$ controls $=39.7 \pm$ 6.2 , Kir2.1 $=39.8 \pm 8.2$, $t$ test, $p=0.95$; duration of calcium response, controls $=$ $75.6 \pm 10.8 \mathrm{~s}, \mathrm{Kir} 2.1=64.2 \pm 8.5 \mathrm{~s}, t$ test, $p=0.4 ; 10 \mu \mathrm{M}$, controls: $n=12$, Kir2.1: $n=19$, amplitude of calcium response, $\Delta R / R_{0}(\%)$ controls $70.7 \pm 23$, Kir2.1 $=$ $68.6 \pm 10.4, t$ test, $p=0.9$; duration of calcium response, controls $79 \pm 13.6 \mathrm{~s}$, Kir2. $1=81.2 \pm 11.4$ s, $t$ test, $p=0.9 ; 200$ $\mu \mathrm{M}$, controls: $n=17$; Kir2.1: $n=20$; amplitude of calcium response, $\Delta R / R_{0}(\%)$ controls $115.3 \pm 15.3$; Kir2.1 $=117.1 \pm$ 23.5; $t$ test, $p=0.95$; duration of calcium response, controls $=111.5 \pm 9.1 \mathrm{~s}$; Kir2.1 $=100.8 \pm 8.3 \mathrm{~s} ; t$ test, $p=0.4$; Figure $1 A-C)$. These results indicated the $\mathrm{Ca}^{2+}$ dynamics in response to odors was very similar in Kir2.1 and in control mice.

$\mathrm{Ca}^{2+}$ imaging is widely used to analyze neuronal activity (Cossart et al., 2005; Kerr et al., 2005; Grienberger and Konnerth, 2012). In our experimental conditions, however, $\mathrm{Ca}^{2+}$ imaging did not have the temporal resolution required to extract the temporal firing patter (i.e., single action potential resolution) of neurons. To overcome this limitation and thoroughly dissect the effect of Kir2.1 expression on the spiking activity of OSNs, using the loose-patch configuration, we recorded spontaneous and odor-evoked activity from dendritic knobs of OSNs, in the intact epithelium.

The spontaneous firing activity of OSNs was recorded for $2-5 \mathrm{~min}$. We found that basal activity exhibited some variability in the firing rate among neurons both in control and in Kir2.1 mice (respectively, four and six mice, 33 and 45 neurons, 4-11 neurons for each animal; Fig. 1E). These data are in agreement with previous studies reporting a consistent variability in the basal firing activity of
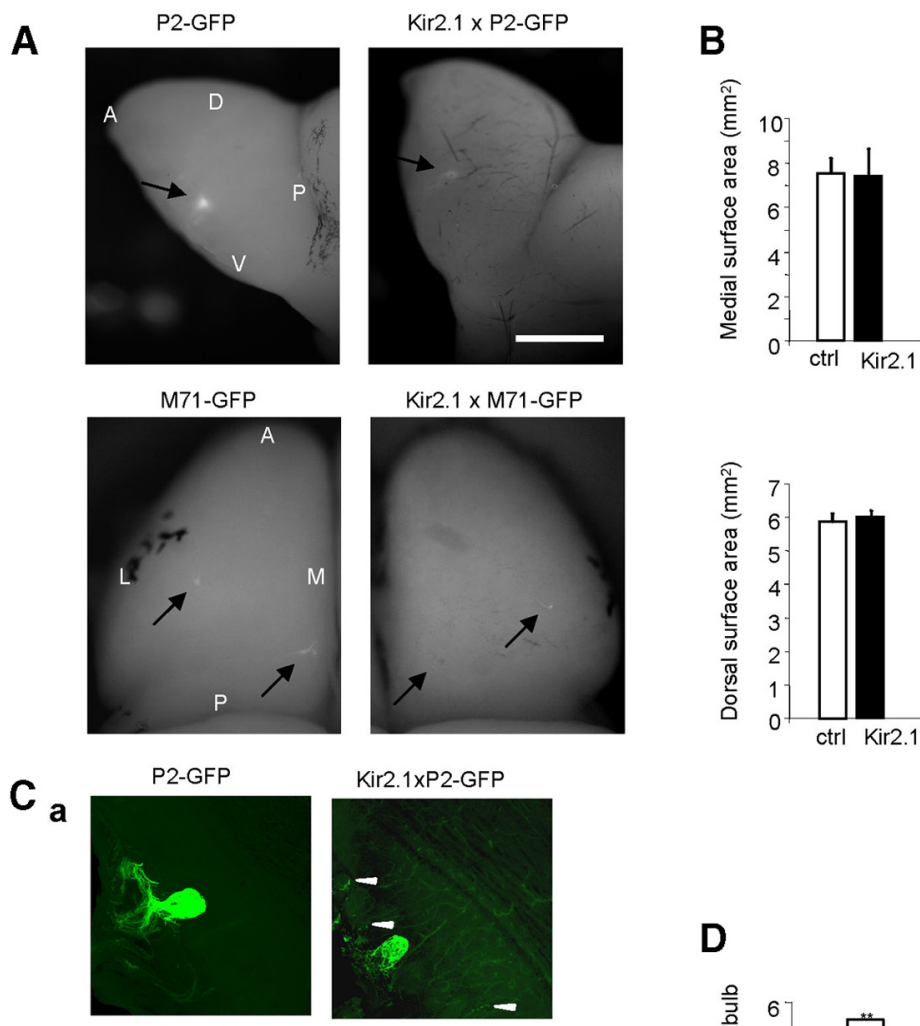

Kir2.1xP2-GFP

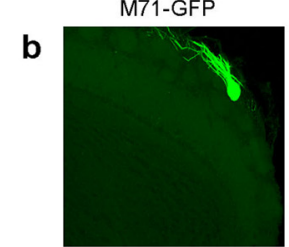

Control

C

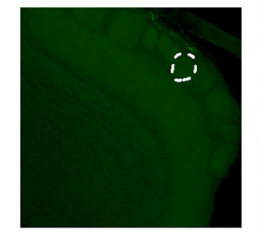

E
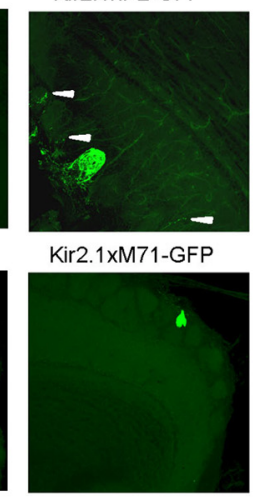

Kir2.1

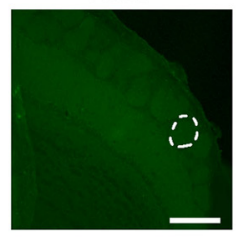

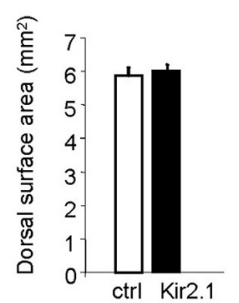

D

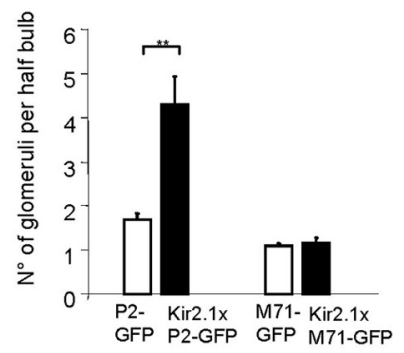

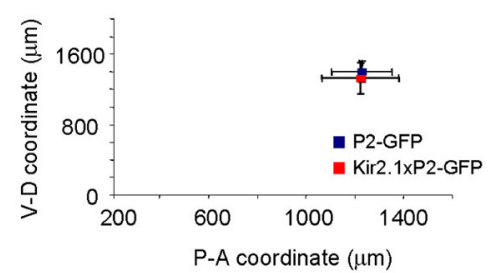

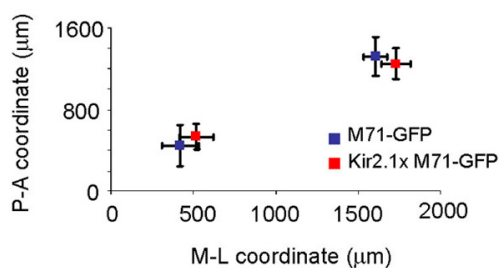

Figure 2. Additional glomeruli in the OB of Kir2.1 mice. $A$, Top, Medial aspect of the OB in P2-GFP, left, and Kir2.1 $\times$ P2-GFP mice, right. Bottom, Dorsal views of the OB of M71-GFP controls, left, and Kir2.1 $\times$ M71-GFP mice, right. Arrows indicate P2-GFP and M71-GFP glomeruli. Scale bar, $1 \mathrm{~mm}$. B, OB size. Top, Area of medial surface (control, $n=6 ;$ Kir2.1, $n=6$ ) and bottom area of the dorsal surface (control, $n=7 ;$ Kir2.1, $n=9$ ) of OB in control and Kir2.1 mice. Data are presented as mean \pm SD. C, Number of glomeruli in the OB of control and Kir2.1 mice. Ca, Examples of GFP-labeled glomeruli in horizontal sections of the OB of P2-GFP control mice (left) and of Kir2.1 $\times$ P2-GFP mice (right), of M71-GFP control mice ( $\boldsymbol{C} \boldsymbol{b}$, left) and Kir2.1 $\times$ M71-GFP mice ( $\boldsymbol{b} \boldsymbol{b}$, right). $\boldsymbol{C}$, Examples of glomeruli in horizontal sections of the OB in control (left) and Kir2.1 (right) mice. Dashed circles outline the profile of a single glomerulus. Scale bar, $200 \mu \mathrm{m} . \boldsymbol{D}$, Number of glomeruli per each half-bulb, and summary of results. Mice per condition: P2-GFP, $n=7$; Kir2.1 $\times$ P2-GFP, $n=7$. M71-GFP, $n=7$; Kir2.1-M71-GFP, $n=6 . t$ test, P2-GFP control versus Kir2.1 $\times$ P2-GFP, ${ }^{* *} p=0.002 ;$ M71-GFP control versus Kir2.1 $\times$ M71-GFP, $p=0.59$. $E$, Graph of the coordinates that define the location of the main glomeruli in the OB of P2-GFP control $(n=5)$ and Kir2.1 $\times$ P2-GFP mice, left ( $n=4, t$ test controls-Kir2.1, V-D, $p=0.3, P-A, p=0.9$ ). Right, Graph of the coordinates that define the location of the main glomeruli in the OB ofM71-GFP control mice $(n=4)$ and of Kir2.1 $\times$ M71-GFP mice $(n=4, t$ test controls-Kir2.1, lateral glomerulus P-A, $p=0.6$; $\mathrm{M}-\mathrm{L}, p=0.07$; medial glomerulus P-A, $p=0.5 ; \mathrm{M}-\mathrm{L}, p=0.24$ ). Blue square, P2-GFP and M71-GFP glomeruli; red square, Kir2.1 $\times$ P2-GFP and Kir2.1 × M71-GFP glomeruli. M, medial; L, lateral; A, anterior; P, posterior; V, ventral; D, dorsal. Data are presented as mean \pm SD. 
A

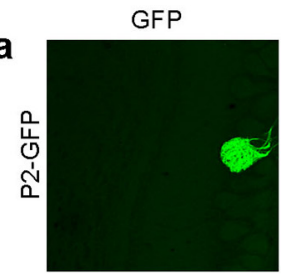

b

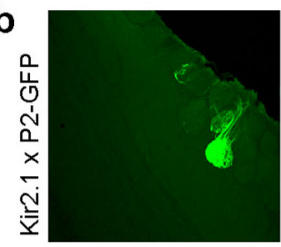

C

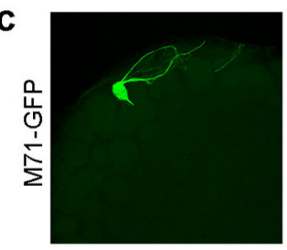

d

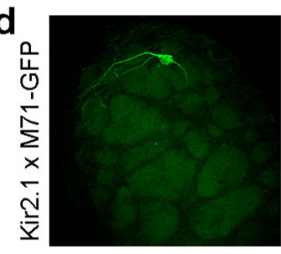

B

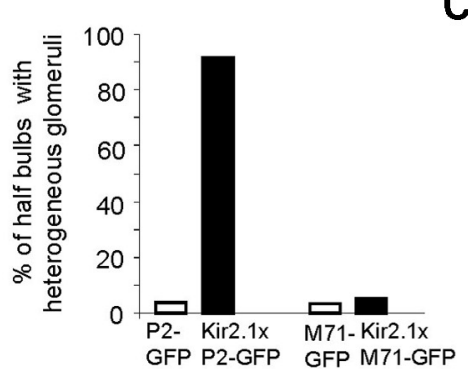

C
OMP
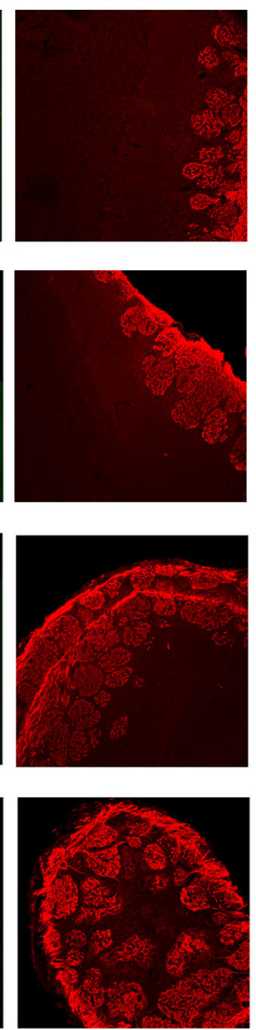

DAPI
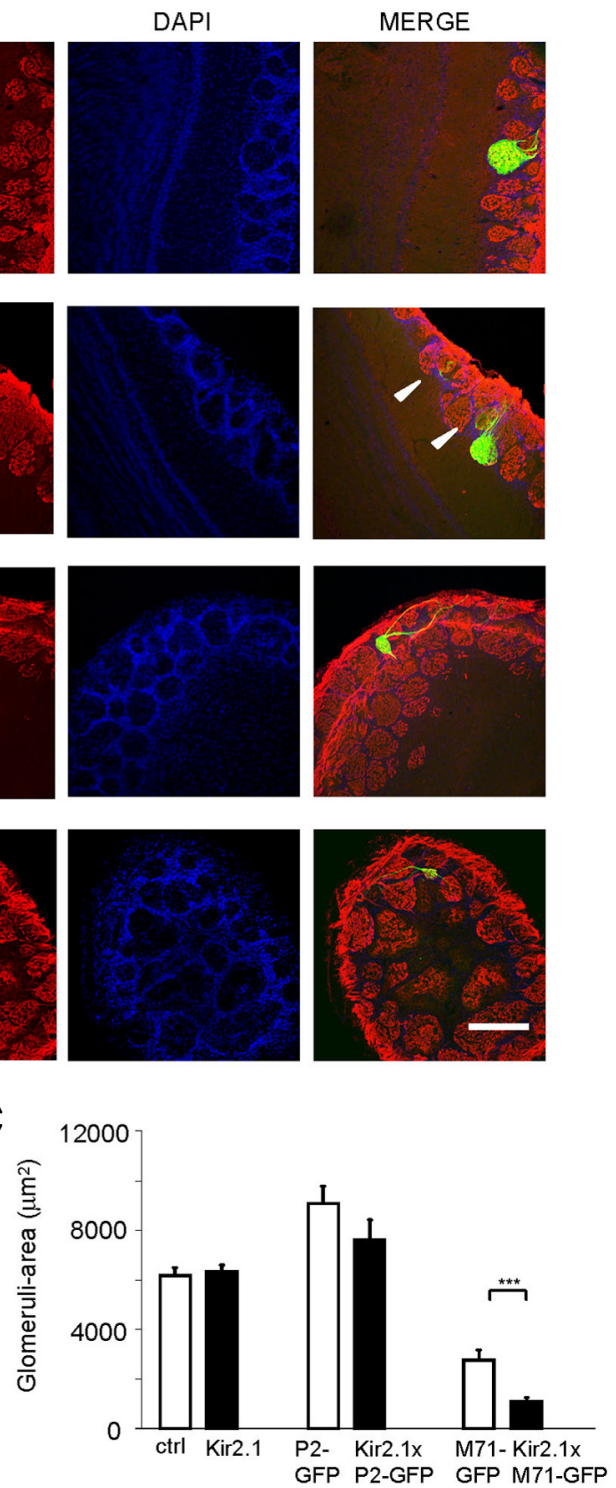

Figure 3. Organization of glomeruli in control and Kir2.1 mice. $A$, Organization of $P 2$ and M71glomeruli was revealed by immunolabeling horizontal sections of the $\mathrm{OB}$ with antibodies against the OMP (red). GFP expressed in P2 and M71-axons (green). Nuclei stained by the nuclear marker, DAPI (blue). $\boldsymbol{A} \boldsymbol{a}, \boldsymbol{A} \boldsymbol{b}, \mathrm{P2}$-axons expressing both GFP and OMP coalesce to form homogeneous glomeruli in P2-GFP and in Kir2.1 × P2GFP mice. Ab, P2-axons also innervate adjacent glomeruli (i.e., heterogeneous glomeruli, arrowheads) in Kir2.1 $\times$ P2-GFP mice. Ac, Ad, M71 glomeruli are formed by OSN axons expressing both GFP and OMP (homogeneous glomeruli) in M71-GFP mice and in most Kir2.1 $\times$ M71-GFP mice. Scale bar, $200 \mu \mathrm{m}$. B, Percentage of half-bulb with heterogeneous glomeruli in P2-GFP $(n=8)$ and in Kir2.1 $\times$ P2-GFP $(n=8)$ and in M71-GFP $(n=8)$ and Kir2.1 $\times$ M71-GFP $(n=$ 8).C, Area of glomeruli in Kir2.1 × P2-GFP mice, in Kir2.1 $\times$ M71-GFP mice, and in controls. The size of glomeruli resulted in similar control and Kir2.1 mice, with the exception of M71-GFP glomeruli that were smaller. Data are presented as mean \pm SEM.

OSNs (Reisert, 2010; Connelly et al., 2013). However, spontaneous firing was significantly reduced in Kir2.1 mice with respect to control, as shown Figure 1D-F (Mann-Whitney $U$ test, one-tail, $\left.p=0.02^{\star}\right)$.

In response to an odor puff, the percentage of responsive neurons was similar in control (79\%) and Kir2.1 (68\%) mice. Odorevoked spiking activity was very similar in OSNs in control and Kir2.1 mice (Fig. 1G-J), confirming the results we obtained with the $\mathrm{Ca}^{2+}$ imaging (see above). In particular we found that both nonsaturating (Fig. $1 G, H$ ) and saturating (Fig. $1 I, J$ ) responses to an odor puff were similar in OSNs in control and Kir2.1 mice (Fig. $1 \mathrm{H}, \mathrm{J}$ ). The firing rate of the evoked responses, estimated as ISI (see Materials and Methods for details), was not significantly $1 L, M ; n=89$ control and 149 Kir2.1 glomeruli, $p=0.002$, Kolmogorov-Smirnov test). The average size of the activated areas was bigger in Kir2.1 mice (Fig. $1 N$; $n=89$ control and 149 Kir2.1 glomeruli, $p<0.005$, Kolmogorov-Smirnov test) while the amplitude of response to a given odor was slightly smaller in Kir2.1 glomeruli than in controls (Fig. $1 O ; n=1531$ Kir2.1 responses, $n=767$ control responses; $p=0.025$, Kolmogorov-Smirnov test).

The sensory map and the organization of glomeruli in the $\mathrm{OB}$ of Kir2.1 mice To study the convergence of OSNs with reduced spontaneous activity to form glomeruli in the $\mathrm{OB}$, mice heterozygous for

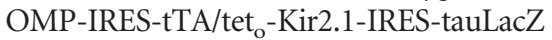
were crossed with mice homozygous for the P2-IRES-GFP or with M71-IRES-GFP allele (Kir2.1 × P2-GFP or Kir2.1 × M71GFP mice). In these mice, sensory neurons expressing the odorant receptor $\mathrm{P} 2$ or M71 coexpress GFP. As a result of this genetic manipulation the corresponding glomeruli can be easily identified in the $\mathrm{OB}$. The overall size of the OB was comparable in Kir2.1 and in control mice (Fig. $2 A, B)$. By P30, in Kir2.1 mice, the P2-expressing axons form one or two distinct glomeruli on the medial and on the lateral side of each bulb (as in controls); however, they also projected to several adjacent glomeruli (from 3 to 9, in one case, 18, mice, $n=7$; Fig. $2 C, D)$. All the additional glomeruli were located in a restricted area, within five glomeruli from the main P2 glomerulus. Due to the late maturation of M71 glomeruli (Zou et al., 2004), we examined M71-GFP mice at P30 and P50. At both these temporal points, the Kir2.1 $\times$ M71-GFP mice presented one glomerulus on each side of the bulb (same as controls) although, occasionally, a few M71-expressing axons also entered one or two adjacent glomeruli ( $n=10$; Fig. $2 C, D)$. As a result of the presence of 

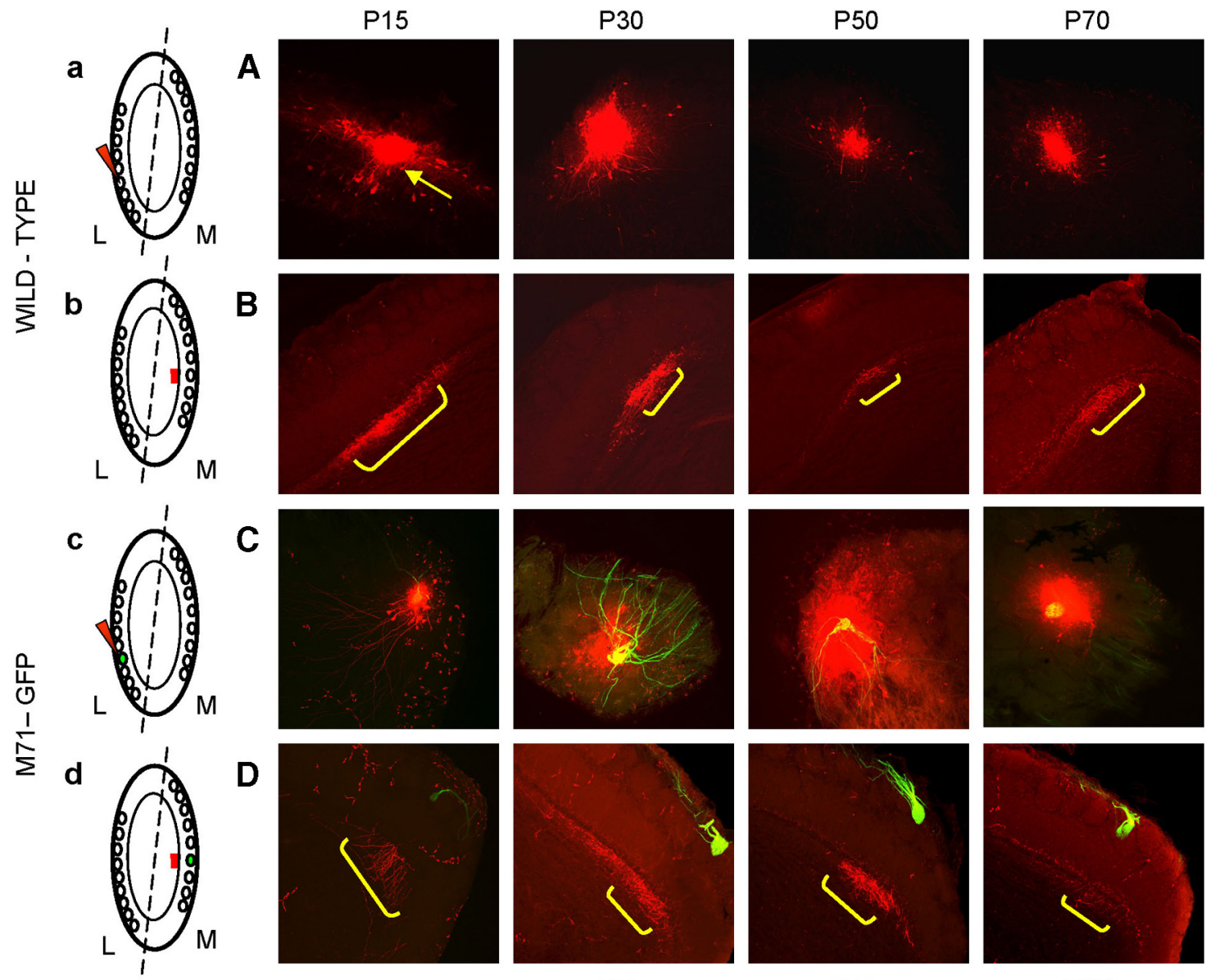

D
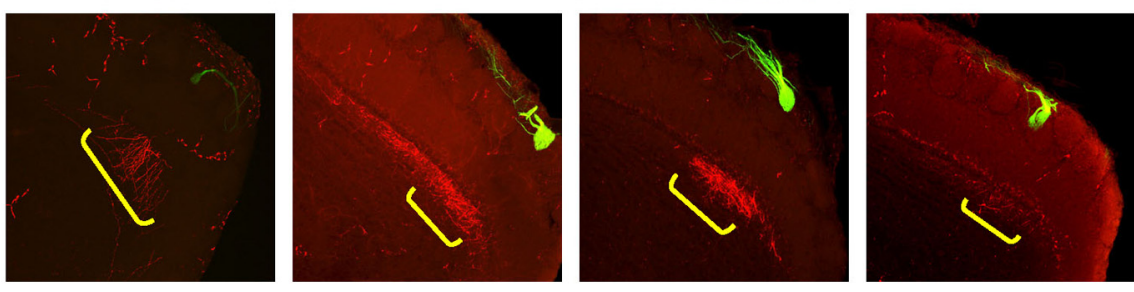

P7

P15

P30

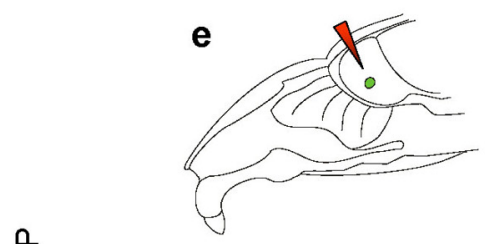

E
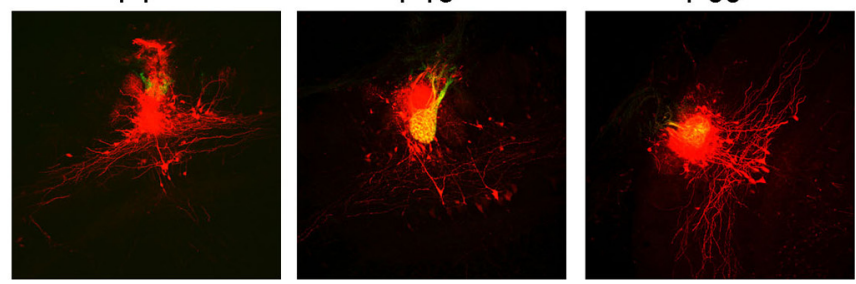

$\frac{0}{U}$
$\frac{1}{2}$
N

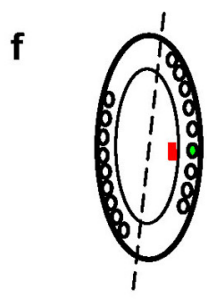

$\mathbf{F}$
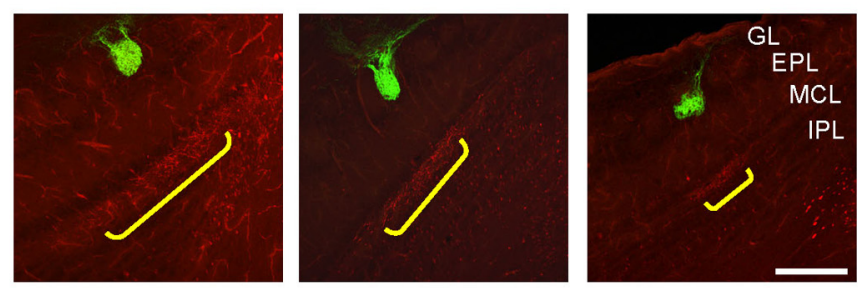

G

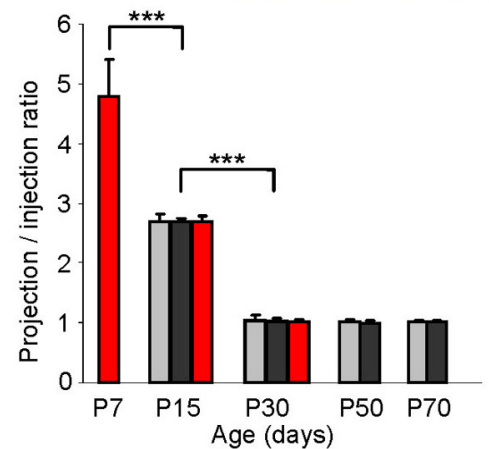

wild type

M71-GFP

P2-GFP

Figure 4. Development of the link between homologous glomeruli in control mice. $\boldsymbol{a}-\boldsymbol{f}$, Schemes of horizontal sections of the $\mathrm{OB}$. The dashed line depicts the line of symmetry between the two maps of homologous glomeruli. $\boldsymbol{a}, \boldsymbol{c}, \boldsymbol{e}$, The red arrowhead indicates the tracer injection targeted to the glomerular layer. $\boldsymbol{b}, \boldsymbol{d}, \boldsymbol{f}$, The red line indicates the ETC projection on the opposite side of the OB. A, Examples of small tracer injections (red spots) targeted to the glomerular layer from P15 to P70. Arrow indicates labeled ETCs. B, Axons of the ETCs labeled (Figure legend continues.) 
additional glomeruli, the olfactory bulb resulted to have a higher number of glomeruli in Kir2.1 than in controls mice $\left({ }^{\star} p<0.05\right.$; Kir2.1 mice, $n=4$ and control mice, $n=4$ ). The location of the main glomeruli for M71 and P2 was superimposable in Kir2.1 $\times$ M71-GFP and Kir2.1 $\times$ P2-GFP and control mice, as shown in Figure $2 E$.

A hallmark of mature glomeruli, which represents a key feature in the organization of the $\mathrm{OB}$, is that they are innervated exclusively by fibers expressing the same OR. To assess the glomerular organization, serial sections of the OB of Kir2.1 $\times$ P2GFP and Kir2.1 $\times$ M71- GFP mice were immunolabeled with antibodies against the OMP, a protein expressed by all mature OSNs (Danciger et al., 1989). The supernumerary glomeruli contained fibers immunopositive for both OMP and for GFP (i.e., axons expressing P2 or M71) along with axons positive only for OMP, but not for GFP (i.e., axons that express a different OR from P2 or M71; Fig. 3Ab,Ad). The main P2 and M71 glomeruli were composed exclusively of fibers positive for OMP and for GFP, i.e., P2 and M71-expressing axons, respectively (Fig. $3 A a, A c)$. These data suggest that the increased number of $\mathrm{P} 2$ and M71 glomeruli can be accounted for by a greater number of heterogeneous glomeruli (Fig. 3B). The size of the main glomeruli was unaltered in most cases analyzed (Fig. 3C). Our data demonstrate that in Kir2.1 mice the organization of the $\mathrm{OB}$ in functional units defined by homogeneous glomeruli is disrupted by the presence of additional heterogeneous glomeruli.

\section{Development of the link between homologous glomeruli}

The perturbed organization of the sensory map in mice with reduced spontaneous activity in OSNs prompted us to examine the second level of topography of the bulb, the connections between homologous glomeruli. To address this question we studied the development of the connections in Kir2.1 and control mice, because our previous studies were limited to adults (Belluscio et al., 2002; Lodovichi et al., 2003). As a result of a possible incomplete refinement and/or mistargeting of the axonal projections of the external tufted cells (ETCs), the intrabulbar link could be less precise and the resulting topographic map more blurred, at early stages of development.

We first analyzed the morphology of the intrabulbar link from P15 to P70 in wild-type mice. To ascertain whether the projection was confined to a single glomerulus (size of the projection), we performed focal injections of an anterograde tracer (tetramethylrhodamine) that were largely restricted to a single glomerulus. We then calculated the ratio between the projection size and the injection size. We knew that in the mature system, analyzed in animals $\geq 3-4$ weeks (Lodovichi et al., 2003) the ratio is 1:1. At $\mathrm{P} 15$, we found that a focal injection gave rise to a broad projection, not exclusively confined to the homologous glomerulus (ratio projection size/injections size $=2.7 \pm 0.12, n=5$; Fig. $4 A, B, G)$. The intrabulbar projections underwent a refinement

(Figure legend continued.) by tracer injections $(\boldsymbol{A})$ ended in anterograde projections (yellow brackets) on the opposite side of the OB. $\boldsymbol{c}, \boldsymbol{d}$, The M71-GFP glomerulus is indicated in green. $\boldsymbol{C}$, Examples of tracer injections targeted to the M71-GFP glomeruli from P15 to P70 and the corresponding projections (yellow brackets) just underneath the M71-GFP homologous glomerulus on the opposite side of the bulb $(\boldsymbol{D})$. $\boldsymbol{e}$, Schematic representation of the hemi-head preparation. In green, the P2-GFP glomerulus on the medial surface of the bulb. $\boldsymbol{E}$, Examples of tracer injections targeted to the P2-GFP medial glomerulus from P7 to P30 and the corresponding projections just underneath the homologous P2-GFP glomerulus on the opposite side of the OB (F). GL, glomerular layer; EPL, external plexiform layer; MCL, mitral cell layer; IPL, internal plexiform layer. Scale bar, $200 \mu \mathrm{m}$. G, Summary of results. Data are presented as mean \pm SD. process between P15 and P30, when they reached the point-topoint projection/injection ratio of $1: 1$, and remained stable throughout adulthood (ratio projection/injection size: P30, ratio $=1.04 \pm 0.09, n=6 ; \mathrm{P} 50$, ratio $=1.03 \pm 0.03, n=4 ; \mathrm{P} 70$, ratio $=1.03 \pm 0.01, n=4, t$ test: $\mathrm{P} 15-\mathrm{P} 30$, ratio ${ }^{* * *} p<0.001$; $\mathrm{P} 30-\mathrm{P} 50$, ratio $p=0.8$; $\mathrm{P} 50-\mathrm{P} 70$, ratio $p=0.9$; Fig. $4 A, B, G)$.

To assess whether the projection was specifically targeted beneath the homologous glomerulus, focal dye injections were performed into the lateral GFP-labeled glomerulus in M71-GFP mice from P15 to P70 (Fig. 4C,D). We found that, at all the time points analyzed, the projection was targeted underneath the medial M71-GFP glomerulus, although at P15 the projection was not exclusively confined to the homologous glomerulus, but larger (ratio $=2.7 \pm 0.35, n=6$; Fig. $4 C, D, G$ ). The refinement process was observed again between $\mathrm{P} 15$ and $\mathrm{P} 30$, when the projection size/injection size ratio was $1: 1(\mathrm{P} 30$, ratio $=1.03 \pm 0.04$, $n=6 ; \mathrm{P} 50$, ratio $=1.01 \pm 0.03, n=3 ; \mathrm{P} 70$, ratio $=1.03 \pm 0.001$, $n=4$; $t$ test: M71 P15-P30, ratio ${ }^{* *} p<0.001 ; \mathrm{P} 30-\mathrm{P} 50$, ratio $p=0.4$; P50-P70, ratio $p=0.9$; Fig. $4 C, D, G)$. Focal tracer injections also were targeted to the P2-GFP glomeruli. In this case, due to the position of the medial glomerulus, buried deep along the medial wall of the $\mathrm{OB}$, the injections were performed in hemihead explant preparations in which the medial side of the bulb was exposed while retaining its connections with the olfactory epithelium and the brain (Fig. 4e; Lodovichi et al., 2003). Due to the early maturation of the P2 glomeruli (Royal and Key, 1999), the size and the targeting of the intrabulbar connections were examined beginning at P7. At all the time points analyzed, again, the axonal projection of the ETCs ended just beneath the homologous glomerulus. Although at earlier stages of development the ETC projection was broader (projection size/injection size ratio at P7, $4.8 \pm 0.6, n=3$; P15, $2.7 \pm 0.09, n=4$; Fig. $4 E-G$ ), it reached the $1: 1$ projection size/injection size ratio at $\mathrm{P} 30$ (ratio $=$ $1.03 \pm 0.03, n=3$; $t$ test P7-P15, ratio ${ }^{* * *} p<0.001, \mathrm{P} 15-\mathrm{P} 30$, ratio ${ }^{* * *} p<0.001$; Fig. $\left.4 E-G\right)$.

\section{Intrabulbar circuitry in Kir2.1 mice}

To analyze the intrabulbar circuitry in Kir2.1 mice, focal tracer injections were targeted to the glomerular layer in Kir2.1 mice from $\mathrm{P} 30$, the age at which a mature, point-to-point connection between homologous glomeruli is present in control animals (see above and Lodovichi et al., 2003) to P70. At all the time points examined, a small injection site corresponded to a projection not confined to a single glomerulus (Fig. $5 A, B, E$ ). Although a reduction in the projection/injection ratio was observed from P30 to P70, it never reached the value of $1: 1$ as in control animals (ratio P30 = $2.33 \pm 0.1, n=9 ; \mathrm{P} 50$ ratio $=2 \pm 0.05, n=5 ; \mathrm{P} 70$, ratio $=1.92 \pm$ $0.13, n=3$; $t$ test: Kir2.1 P30-P50 ratio ${ }^{* * *} p<0.001$, Kir2.1 P50 $\mathrm{P} 70$ ratio $p=0.3, \mathrm{P} 30$ wt-P30 Kir2.1 ratio ${ }^{\star * *} p<0.001, \mathrm{P} 50$ wt- P50 Kir2.1 ratio ${ }^{\star * *} p<0.001, \mathrm{P} 70$ wt-P70 Kir2.1 ratio $\left.{ }^{\star * *} p<0.001\right)$.

Focal tracer injection targeted to the $\mathrm{P} 2$ medial glomerulus in Kir2.1 $\times$ P2-GFP mice ended in a projection just beneath the homologous glomerulus (Fig. $5 C-E, \mathrm{P} 30$, ratio $=2.37 \pm 0.08$, $n=6, t$ test ratio P2-GFP-Kir2.1 $\times \mathrm{P} 2-\mathrm{GFP}^{* * *} p<0.001$; P30, ratio Kir2.1 $\times$ P2-GFP vs Kir2.1 $p=0.5$ ). Therefore the specific targeting of the anterograde projection was not affected in Kir2.1 mice. The specific targeting between M71 glomeruli in Kir2.1 $\times$ M71-GFP mice could not be examined, since identifying and targeting such small glomeruli were extremely challenging.

All together these data indicated that the connection between the main glomeruli was preserved in Kir2.1 mice, although it was not confined exclusively to isofunctional glomeruli due to the lack of refinement of the axonal projections of the ETCs. 


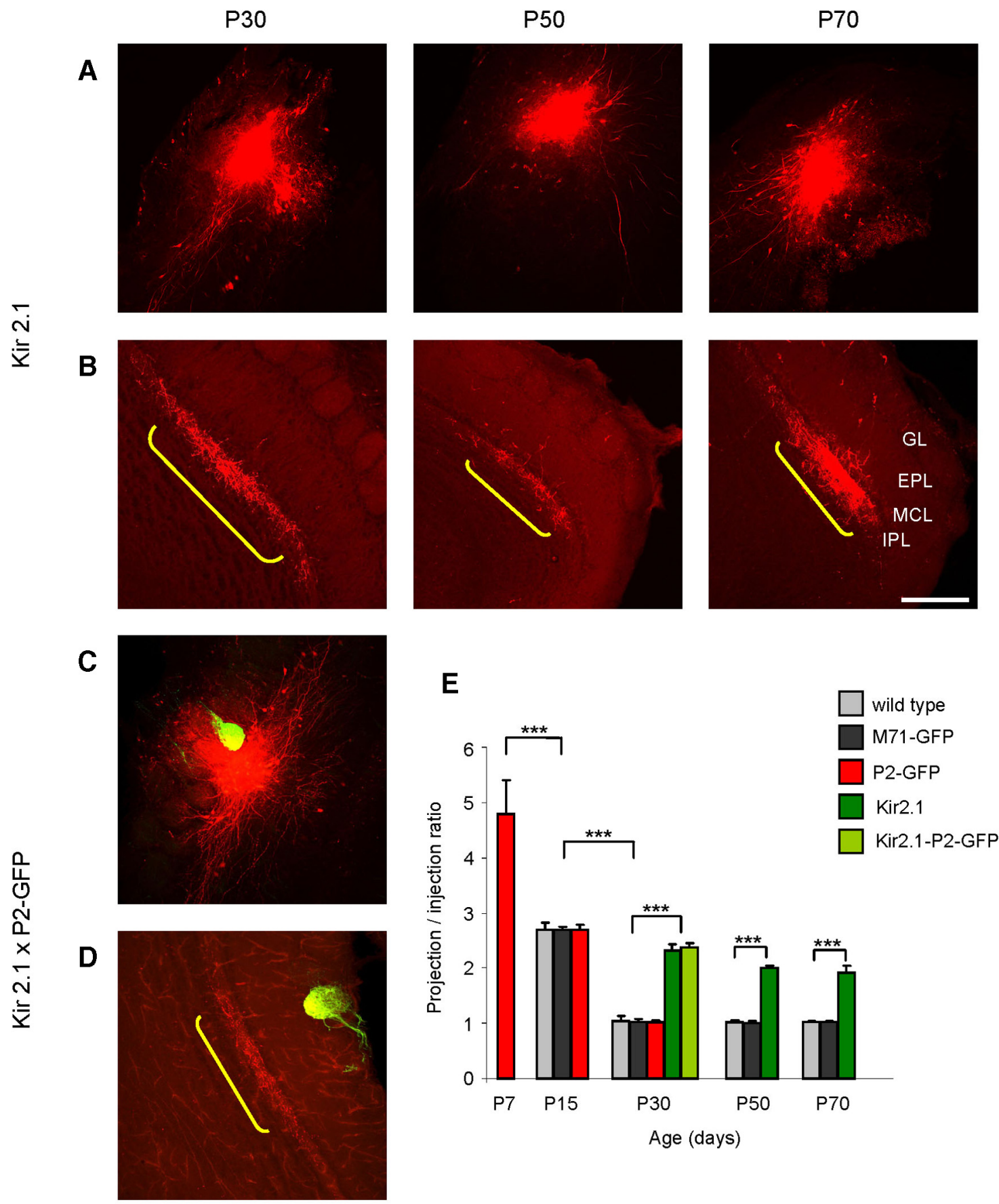

Figure 5. Unrefined intrabulbar circuitry in Kir2.1 mice. A, Examples of focal tracer injections (red spots) targeted to the glomerular layer in Kir2.1 mice from P30 to P70. B, ETC axons labeled in $A$ give rise to anterograde projections (yellow brackets) on the opposite side of the bulb, which are larger than the corresponding injection sites. $C$, Tracer injection targeted to the medial P2-GFP glomerulus and the corresponding projection underneath the homologous P2-GFP glomerulus (D). GL, glomerular layer; EPL, external plexiform layer; MCL, mitral cell layer; IPL, internal plexiform layer. Scale bar, $200 \mu \mathrm{m}$. $E$, Summary of results. Data are presented as mean \pm SD.

\section{Development of mitral cell apical dendrite in Kir2.1 mice}

We found that the developmental refinement of the OSN and ETC axonal projections is perturbed in Kir2.1 mice. We asked whether the postsynaptic targets of the OSNs, the mitral cells (MCs), exhibited any effect related to their developmental maturation in Kir2.1 mice. Mature mitral cells extend a single apical dendrite into a single glomerulus to contribute to the organization of the odor column. This single apical dendrite remains after the withdrawal of other, supernumerary dendrites, a process that is completed in the first postnatal week (Lin et al., 2000). We found no difference in the developmental remodeling of the api- cal dendrite of MCs in Kir2.1 mice versus controls (from P6 to P8 mice). At this developmental stage, indeed, most MCs presented a single apical dendrite as in controls (MCs with single apical dendrite at $\mathrm{P} 6=91.6 \%$ in controls, $91 \%$ in Kir 2.1 mice, at $\mathrm{P} 7=$ $96.7 \%$ in controls and $96.8 \%$ in Kir2.1 mice, at P8 $=98 \%$ in controls and 97\% in Kir2.1 mice; Fig. $6 A-D$ ).

\section{Olfactory discrimination behavior in Kir2.1 mice}

The altered organization of the anatomical and functional maps of the OB could affect olfactory behavior. To address this question we studied the ability of Kir2.1 mice to discriminate between 
A
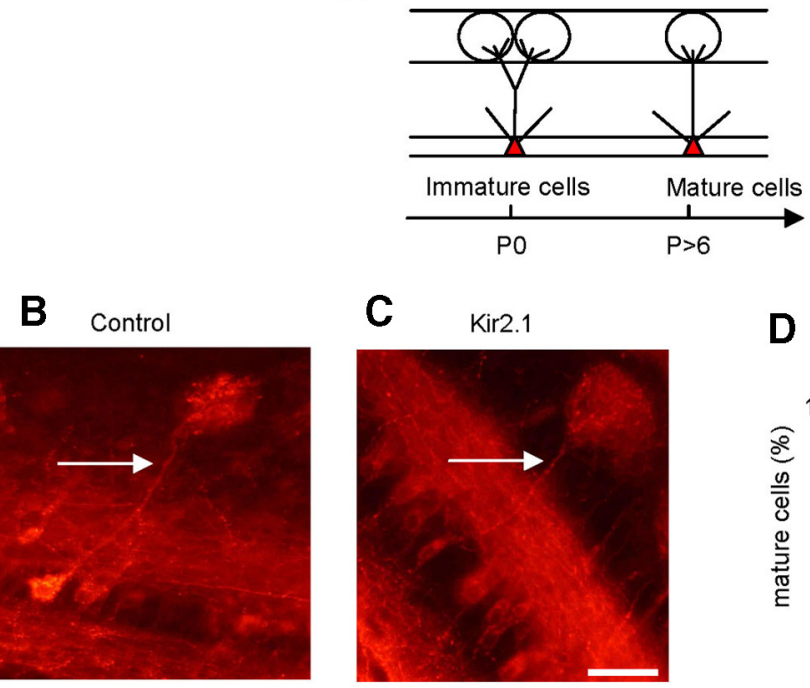

D

E

Training phase (day 1-4)

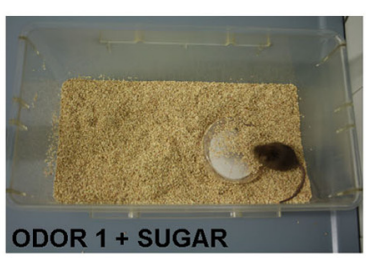

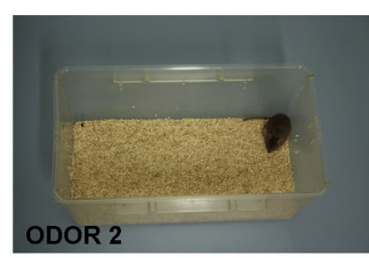

I

H

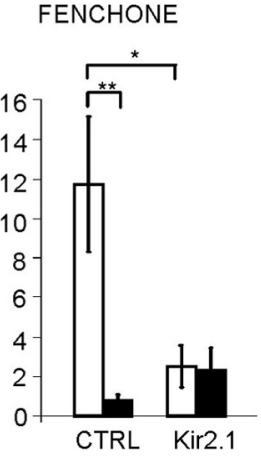

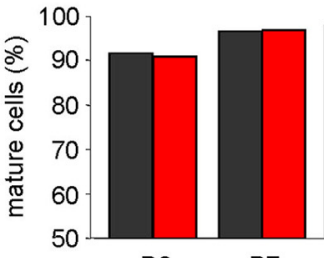

P6

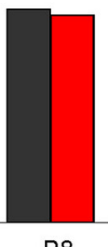

P8 a Kir2.1

口 control
G

$$
\text { 2-HEPTANOL }
$$

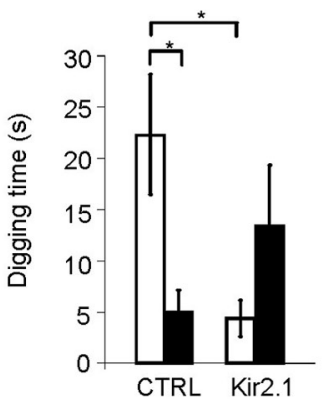

\section{F}

Discrimination test (day 5)

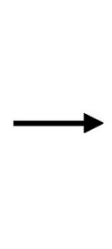

ODOR 1

ODOR 2

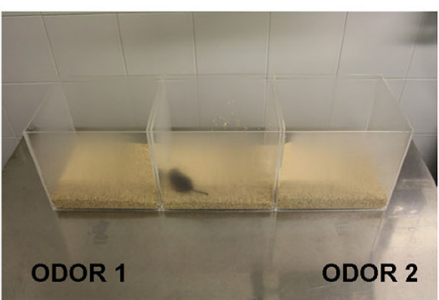

J

CARVONE

$2-M B / c B$
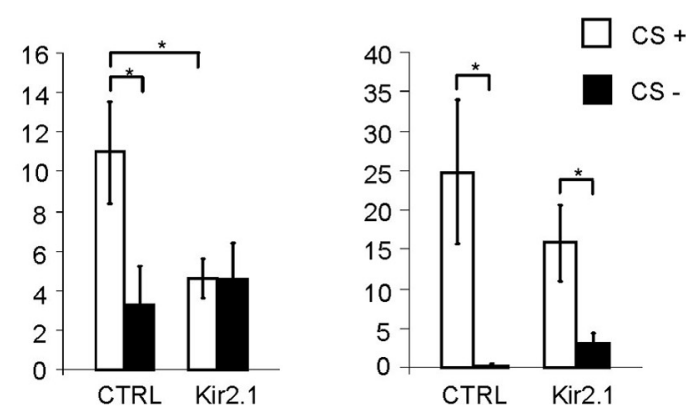

Figure 6. Developmental refinement of the apical dendrite in MCS. $\boldsymbol{A}$, Schematic representation of the developmental withdrawal of the extra apical dendrites. $\boldsymbol{B}-\boldsymbol{C}$, Examples of $\mathrm{MCS}$, retrogradely labeled by Dil, in horizontal sections of the $O B$, in control $(\boldsymbol{B})$ and in Kir2.1( $\boldsymbol{C}$ ) mice at P7. In both cases $(\boldsymbol{B}, \boldsymbol{C})$ a single apical dendrite (arrow) ends in an apical tuft within a single glomerulus. $\boldsymbol{D}$, Summary of results (P6: Kir2.1 mice, $n=6$, wild-type mice, $n=4$; P7: Kir2.1 mice, $n=5$, wild-type mice, $n=4$; P8: Kir2.1 mice, $n=6$, wild-type mice, $n=4$ ). Scale bar, $100 \mu$ m. Odor discrimination tests in control and Kir2.1 mice. E, Control and Kir2.1 mice were trained for $4 \mathrm{~d}$ to discriminate between the conditioned odor (odor $1+$ sugar, $\mathrm{CS}+$ ) and the unconditioned odor (odor 2, (S-). On the fifth day $(\boldsymbol{F})$ the animals were tested in a three-chamber apparatus and the digging time for each odor (without sugar) of the related pair was scored. $\mathbf{G}-\mathbf{J}$, Digging time for each pair of odors tested. Bars indicate SEM. ${ }^{*} p<0.05,{ }^{* *} 0.001<p<0.01$.

two odors. We found that the altered connectivity was confined around the main glomeruli, for both the sensory map and for the intrabulbar connections. We reasoned that the Kir2.1 mice could have difficulties in discriminating odorants that elicit very similar spatial maps of activated glomeruli, such as enantiomers. Enantiomers, mirror symmetric pairs of molecules that differ only in their optical activity, are represented by similar functional maps that differ for one or a few activated glomeruli located in a restricted area, in rodents. It has been shown that the spatial pattern of glomerular activity provide sufficient information to discriminate molecular shapes (Linster et al., 2001; Rubin and Katz, 2001;
Kobayakawa et al., 2007; Clarin et al., 2010; Mori and Sakano, 2011; Murthy, 2011).

To assess the discrimination capabilities of Kir2.1 mice, we performed an olfactory discrimination test (Schellinck et al., 2001) using four different couples of odorants. Mice were trained for $4 \mathrm{~d}$ to associate either of the two related odors to a food reward (sugar). On the fifth day, the sugar reward was removed and the animal ability to discriminate between the two related odors was tested. The lengths of time the mouse spent investigating, digging, and sniffing the odorants were measured (see methods for details). If the animal spends most of the time investigating the 
A

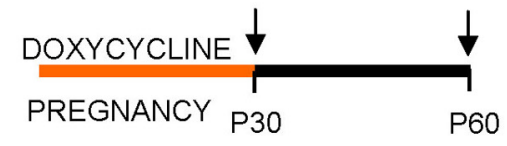

B POST DOXY 30 days

POST DOXY 60 days

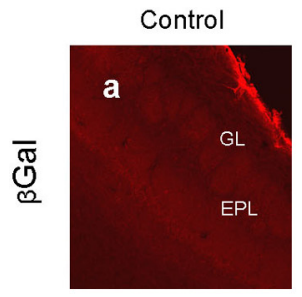

C
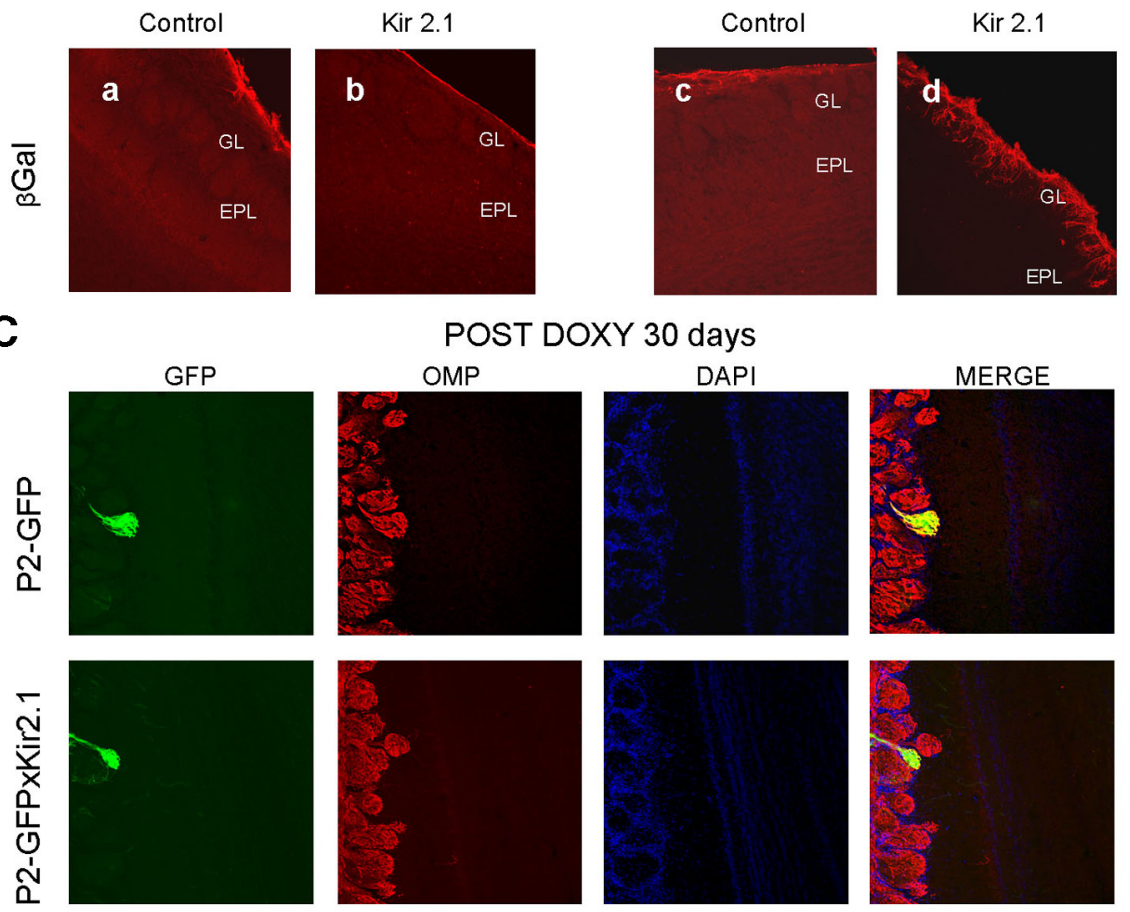

D
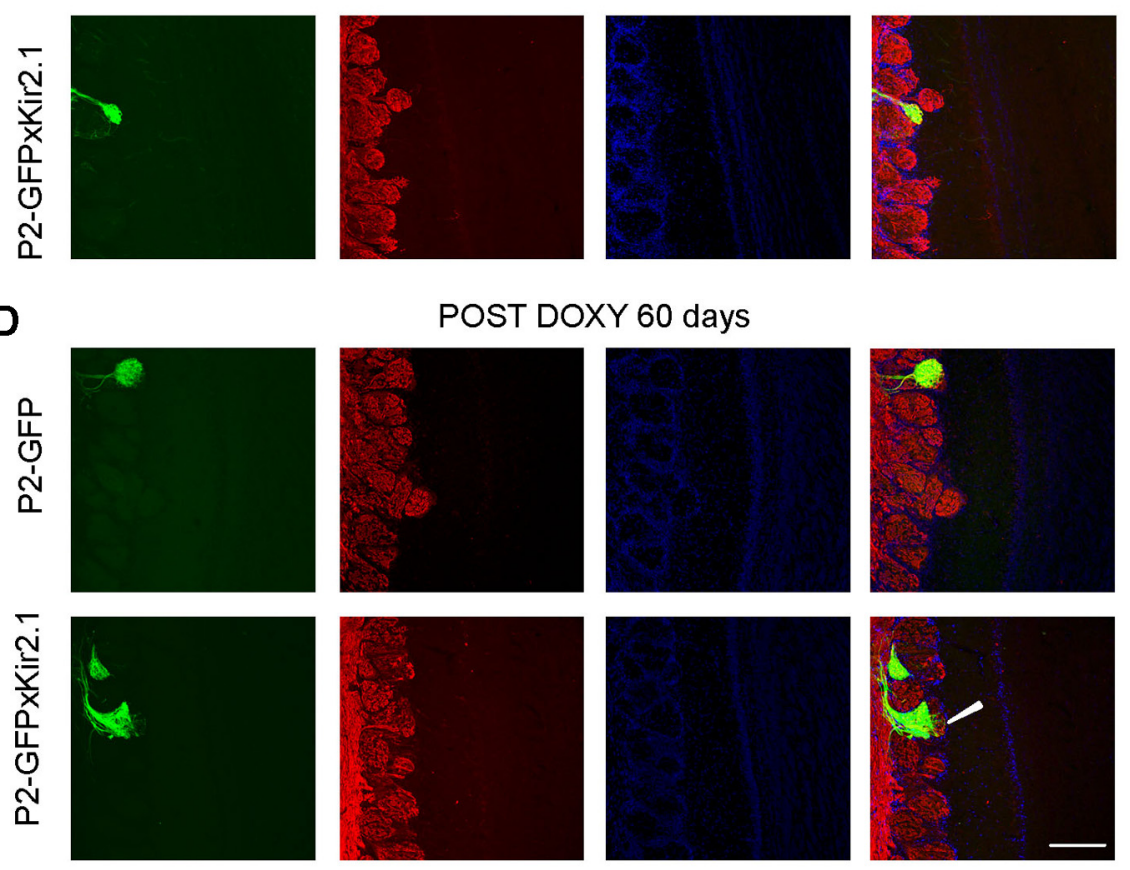

E
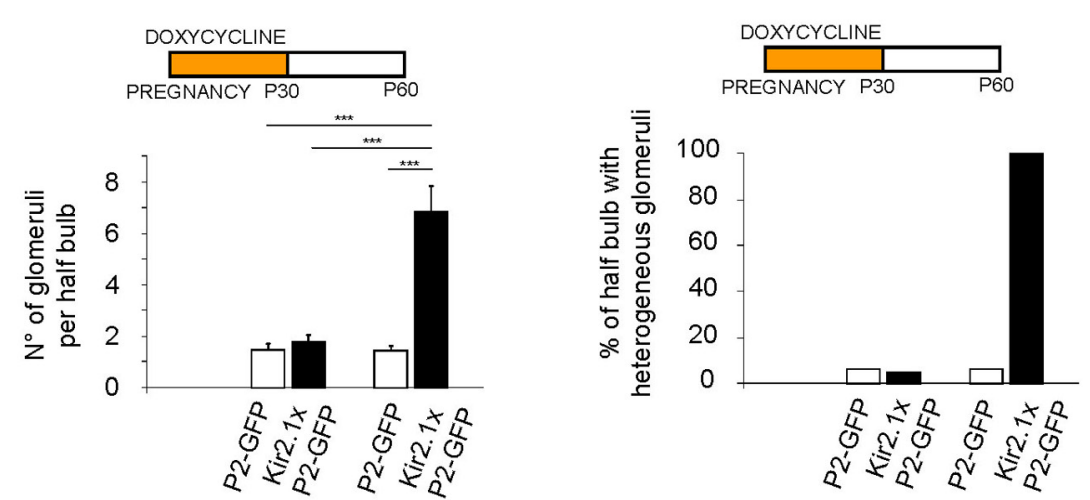

Figure 7. Sensory map plasticity in Kir2.1 mice. $A$, Schematic of the experimental strategy. Doxycycline is supplied with the food throughout the gestation and in newborn mice until P30. The sensory map is analyzed at $\mathrm{P} 30(\boldsymbol{C})$ and at $\mathrm{P} 60$ (D). In the latter case, Kir2.1 is re-expressed from P30 to P60. B. Horizontal sections of the $O B$ immunostained with antibodies against $\beta$-gal in conditioned odor, this indicates that the animal is able to discriminate the two odors.

We found that Kir2.1 mice were unable to discriminate between odors that elicit very similar spatial patterns of activation, such as the couples of the enantiomers 2-heptanol $(+)$ and $(-)$, fenchone $(+)$ and $(-)$, carvone $(+)$ and $(-)$, but retained the ability to distinguish between odorants that presented a more distinct spatial pattern of activated areas, such as 2-MB acid and cb acid (Figure 6E-J).

\section{Overexpression of Kir2.1 in adults}

disrupted the already

refined connectivity

Spontaneous activity has always been thought to play a prominent role in early stages of development (Goodman and Shatz, 1993; Huberman et al., 2008). Once the sensory systems become responsive to sensory stimuli, evoked activity contributes to the stabilization and further refinement of neuronal connections (Shatz, 1996; Hensch, 2004). Whether spontaneous activity can modulate synaptic connections in adult life remains largely unknown.

To address this point we took advantage of the inducible nature of the Kir2.1 construct. In one group of experimental animals, the expression of the Kir2.1 channel was suppressed by doxycycline administration in the food, during gestation, and in the first $30 \mathrm{~d}$ of postnatal life (P30) in Kir2.1 mice (Fig. 7A). In a second group of animals, at P30 the administration of doxycycline was suspended, allowing the Kir2.1 channel to be expressed until P60 (Fig. 7A).

We analyzed the effect of suppression/ re-expression of Kir2.1 on both levels of the topographic organization of the olfac-

\section{$\leftarrow$}

wild-type control $(\boldsymbol{B} \boldsymbol{a})$ and in Kir2.1 $(\boldsymbol{B} \boldsymbol{b})$ mice, both treated with doxycycline until P30 $(\boldsymbol{B} \boldsymbol{a}, \boldsymbol{B} \boldsymbol{b})$. In the Kir2.1 mice $(\boldsymbol{B} \boldsymbol{b})$, $\beta$-gal (i.e., Kir2.1) expression is abolished, due to the doxycycline administration. $\boldsymbol{B C}, \boldsymbol{B d}$, Horizontal sections of the $\mathrm{OB}$ immunostained with antibodies against $\beta$-gal in wild-type control (BC) and in Kir2.1 (Bd) mice, analyzed at P60. In Kir2.1 mice $\beta$-gal is clearly re-expressed. $C$, Organization of P 2 glomeruli was revealed by immunolabeling horizontal sections of the $O B$ with antibodies against $\mathrm{OMP}$ (red). GFP expressed in P2 axons (green). Nuclei stained by the nuclear marker, DAPI (blue). Upon doxy administration, at P30, P2-axons converge into a single homogeneous glomerulus in control and Kir2.1 mice. D, At P60, P2-axons converge into a single glomerulus in control and Kir2.1 mice; however, they also project to adjacent heterogeneous glomeruli in Kir2.1 mice (arrowhead). Scale bar, $200 \mu \mathrm{m}$. E, Summary of results. As indicated by the schematic on top in each graph: left, results at $\mathrm{P} 30$; right, results at P60. 
tory bulb, namely the glomerular map and the intrabulbar connections. We found that doxycycline administration until P30 completely abolished the expression of Kir2.1 (Fig. 7B). Analyzing the sensory map at $\mathrm{P} 30$, we found that the stereotypical pattern of convergence of the P2 OSN axons was restored (control mice, $n=3$; Kir2.1 mice, $n=3$; test, $p=0.4$; Fig. $7 C, E$ ). Studying the sensory map at P60, in mice that expressed Kir2.1 gene from P30 to P60, we found that P2-axons converge to form not only the main homogenous glomeruli, but they also targeted several additional heterogeneous glomeruli (Fig. $7 D, E$; control mice, $n=3$; Kir2.1 mice, $n=4$, control-Kir2.1 P60 $t$ test, ${ }^{* * *} p<$ 0.0001; Kir 30-Kir $60 t$ test, ${ }^{* * *} p<0.0001$; Fig. $\left.7 D, E\right)$.

We then analyzed the intrabulbar connections. In the first experimental design, a small tracer injection targeted to the glomerular layer in Kir2.1 mice at P30 ended in a small projection, confined to a single glomerulus (as in controls), on the opposite side of the bulb (Fig. $8 A-E$, K; wild-type controls + doxy, P30, mice, $n=3$, ratio $=1.01 \pm 0.03$, Kir2.1 mice + doxy, P30, mice, $n=3$, ratio $=1.1 \pm 0.09, t$ test ratio Kir2.1-wt mice, $p=0.2$ ).

A focal tracer injection targeted to the glomerular layer at P60 in Kir2.1 mice that overexpressed Kir2.1channel from P30 to P60, gave rise to a projection that was broader than in controls (Fig. $8 F-K$; wild-type control mice: $n=3$, ratio $=1.1 \pm 0.09$; Kir2.1 mice: $n=3$, ratio $=1.8 \pm 0.2 ; t$ test ratio Kir2.1-controls (P60), $\left.{ }^{* *} p=0.002\right)$. The projection size/injection size ratio was smaller at P60 in Kir2.1 mice treated with doxycycline until P30 than in Kir2.1 mice at P30 $\left(^{* * *} p \leq 0.001\right)$.

\section{Discussion}

Perturbed neural wiring and functional maps in Kir2.1 mice In this paper we studied circuit formation and function in the $\mathrm{OB}$ of mice genetically modified to have reduced spontaneous activity in OSNs (Kir2.1 mice; Yu et al., 2004). We found that the basal spiking activity was significantly reduced in OSNs of Kir2.1 mice with respect to controls. In response to odor stimulation, however, the $\mathrm{Ca}^{2+}$ response and the firing pattern were superimposable in control and Kir2.1 mice. These data suggest that odorant stimuli, at all the concentrations tested, were capable of overcoming the hyperpolarization of OSNs in Kir2.1 mice. It is worth noting that OSNs have high input impedance (Lynch and Barry, 1989; M. Ma et al., 1999; Grosmaitre et al., 2006) and small odorevoked currents may be sufficient to cause suprathreshold depolarization. Consistent with our results, previous studies have shown that although basal activity is reduced in neurons expressing Kir2.1, once threshold is reached, stimulus-evoked activity in control and overexpressing Kir2.1 neurons is similar (Burrone et al., 2002). These data indicate that Kir2.1 mice are a useful model to dissect the role of spontaneous activity in the topographic and functional organization of the $\mathrm{OB}$.

Odor-evoked activity also was clearly recorded in glomeruli of Kir2.1 mice although the functional maps were coarser than in controls. A recent paper (L. Ma et al., 2014) reported that methyl valerate did not elicit responses in the $\mathrm{OB}$ of Kir2.1 mice, in contrast to our extensive data. It is not clear what the difference is, but we note that our study used a large suite of odorants ( 97 chemically diverse odorants, including ethyl valerate, an odor similar to methyl valerate). Our in vivo data are also corroborated by in vitro recordings demonstrating clear odor response in Kir2.1overexpressing OSNs.

We found a higher number of active spots to stimuli that resulted in a larger overall area of response, compared with controls. Each glomerulus was responsive to a higher number of odorants, although the odor responses were smaller in amplitude in Kir2.1 glomeruli than in controls. It has been shown that the spots of the activated area correspond to single glomeruli and they derived primarily from the activation of the sensory neuron axons (Meister and Bonhoeffer, 2001; Belluscio et al., 2002; Soucy et al., 2009). A hallmark of mature glomeruli is that they are innervated exclusively by sensory axons expressing the same OR (Treloar et al., 2002). We found that OSN axons expressing the same OR project to multiple adjacent glomeruli in Kir2.1 mice, a proper feature of early stage of development (Royal and Key, 1999; Lodovichi and Belluscio, 2012). This pattern of projection can explain the higher number of activated glomeruli in response to a given odorant. The spatial vicinity of these additional heterogeneous glomeruli is likely to account for the larger size of the spots. The heterogeneous organization of glomeruli can explain the smaller amplitude of the response, since not all the fibers within a given glomerulus are responsive to a given odorant. Having different types of ORs, each glomerulus is responsive to a higher number of odors, resulting in wider molecular receptive range. These data suggest that the functional alterations reflected with remarkable precision the unrefined connectivity of the sensory map of Kir2.1 mice.

In addition, we found that in Kir2.1 mice the intrabulbar connections, although preserved, did not undergo the refinement process that takes place between P15 and P30 in control animals, resulting in spread of connections. The axonal projections of the ETCs also were coarser in the absence of sensory experience due to naris occlusion (Marks et al., 2006) although the defects were more severe in that case. The absence of evoked activity appears to cause a significant enlargement of the ETC projections while reduced spontaneous activity prevents their refinement. Our data show that reduced spontaneous activity in Kir2.1 mice affects the refinement process of both levels of topography in the OB.

Although the mechanism underlying neural circuit refinement remains to be clarified, different scenarios can be envisioned. (1) Disrupted spontaneous activity is likely to influence the levels of second messengers such as cyclic nucleotides and $\mathrm{Ca}^{2+}$ that are known to play a critical role in axon targeting in several systems (Song et al., 1997; J.Q. Zheng and Poo, 2007) including the OS (Maritan et al., 2009; Lodovichi and Belluscio, 2012). (2) Spontaneous firing could facilitate the action of factors, such as neurotrophic factors, in the activity-dependent competition that operates on branch stability or formation (Thoenen, 1995; Bonhoeffer, 1996). It has been shown that the action of neurotrophins has to be coupled to afferent spontaneous activity to modulate neuronal plasticity in the developing visual cortex (Caleo et al., 1999). In addition, the action of trophic factors on axon growth in retinal ganglion cell is dramatically enhanced by activity (Goldberg et al., 2002). It is worth noting that the OR is thought to determine not only odor-evoked activity but also specific pattern of spontaneous activity, in OSNs in Drosophila (Hallem and Carlson, 2004) and also in mice (Connelly et al., 2013). Therefore, an activity-based competition could modulate the response of OSN and ETC axons to trophic factors and/or guidance molecules present in the bulb, favoring the refinement, pruning, and stabilization of axon arbors.

\section{Altered odor discrimination ability in Kir2.1 mice}

Analyzing the olfactory behavior, we found that Kir2.1 mice were not able to discriminate odorants that elicited similar spatial maps of activated glomeruli but retained the ability to discriminate odorants that activated a more distinct spatial pattern of glomeruli. These results could be explained by the alterations we found in the anatomical and functional maps of the OB in Kir2.1 
A
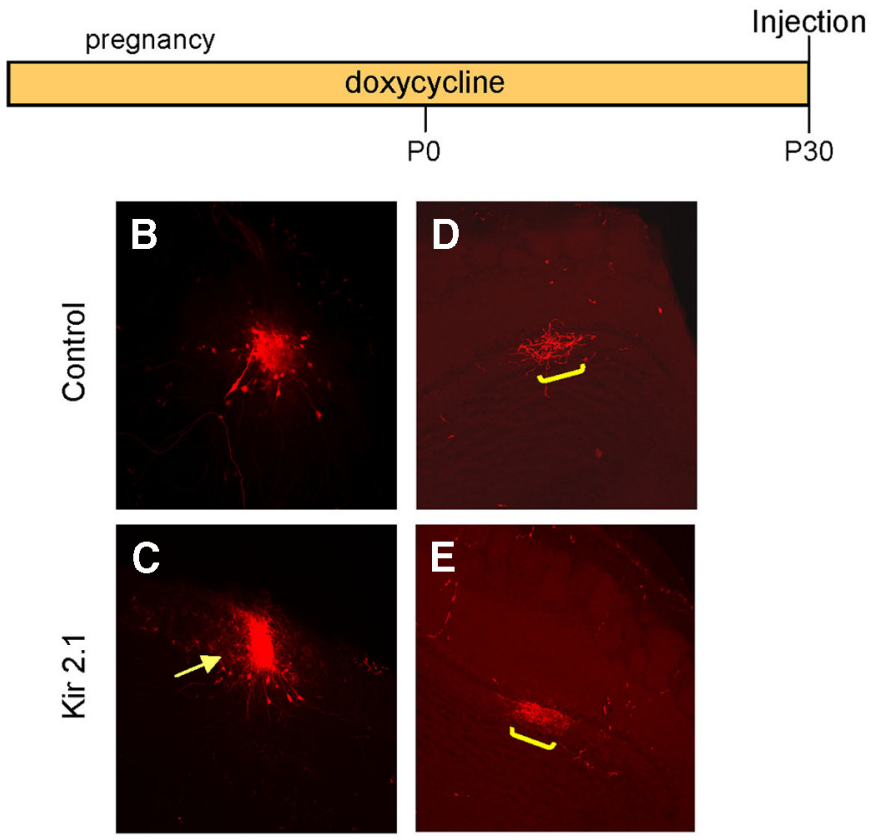

$\mathbf{F}$
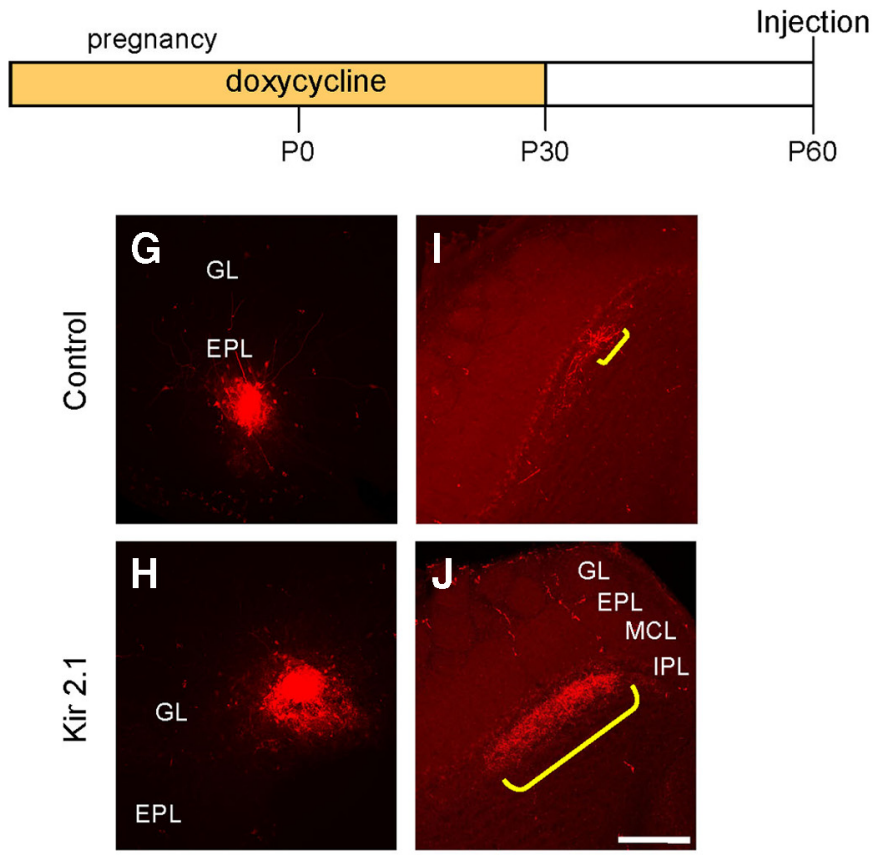

K

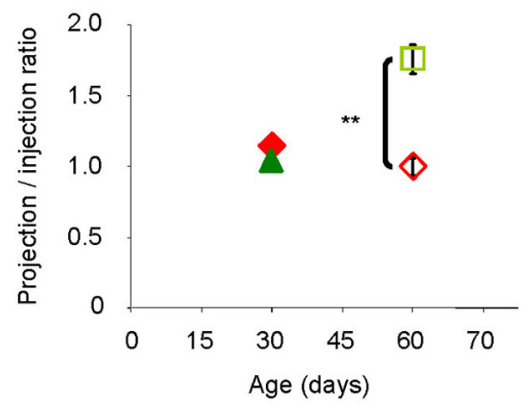

Figure 8. Plasticity of the intrabulbar link in Kir2.1 mice. $A$, Schematic of experimental strategy. $B, C$, Examples of focal tracer injections targeted to the glomerular layer of control ( $\boldsymbol{B}$ ) and Kir2.1 ( $(\boldsymbol{C}$ mice (supplied with doxycycline). Arrow, labeled ETCs. $\boldsymbol{D}, \boldsymbol{E}$, The patchy corresponding projections (yellow bracket) on the opposite side of the OB. $F$, Schematic representation of the experimental strategy. Doxycycline administration is suspended at P30 and tracer injection targeted to the glomerular layer in control mice. The functional maps elicited by the $(-)$ or $(+)$ element of each pair of the enantiomers (Linster et al., 2001; Rubin and Katz, 2001; Clarin et al., 2010) differ for a few glomeruli located in a restricted region. That region is superimposable to the area where we found additional heterogeneous glomeruli and a broader link between homologous glomeruli. Therefore the specific spatial pattern that contributes to the neural representation of enantiomers appears to be disrupted by the unrefined connectivity of the OB in Kir2.1 mice. Discrimination of odorants that are represented by glomeruli scattered in more distinct locations in the bulb was not significantly affected. Our data corroborate the view that spatial maps in the $\mathrm{OB}$ contribute to the neural representation of different odor molecules (Rubin and Katz, 2001; Kobayakawa et al., 2007).

\section{Neuronal plasticity in the \\ olfactory bulb}

Sensory experience modulates the development of neuronal circuitry mostly within a defined period of time (the critical period) during which the brain is particularly plastic (Hensch, 2004). Beyond this critical period the wiring of neural circuitry is hardly affected by changes in evoked activity. Unlike other sensory modality, it has been shown that neural circuits in the OB, namely the link between homologous glomeruli, remain sensitive to manipulation of evoked activity also in adulthood (Cummings and Belluscio, 2010).

The effect of the spontaneous activity on mature neuronal circuits has been scarcely examined. Indeed the role of spontaneous activity is generally thought to be confined to the early phase of development (Shatz, 1996; McLaughlin et al., 2003; Spitzer, 2006; Huberman et al., 2008). Our data demonstrated that the $\mathrm{OB}$ differs significantly from this paradigm. We found that the re-expression of Kir2.1 in adult animals induces a regression of the already refined connectivity of the glomerular map and of the link be-

\section{$\leftarrow$}

and Kir2.1 mice at P60. Between P30 and P60 no doxycycline is supplied to allow overexpression of the Kir2.1. $\boldsymbol{G}, \boldsymbol{H}$, Examples of focal injections in the glomerular layer in control $(\boldsymbol{G})$ and in Kir2.1 $(\boldsymbol{H})$ mice and the corresponding projections (yellow bracket) on the opposite side of the bulb in control $(I)$ and Kir2.1 $(J)$ mice. In Kir2.1 mice $(J)$ the projection is clearly broader. Scale bar, $200 \mu \mathrm{m}$. GL, glomerular layer; EPL, external plexiform layer; MCL, mitral cell layer; IPL, internal plexiform layer. $\boldsymbol{K}$, Summary of results. Data are presented as mean $\pm S D{ }^{* *} 0.001<p<0.01$. 
tween homologous glomeruli to a coarser status. These results indicate that the neuronal wiring in the $\mathrm{OB}$, when formed correctly, remained sensitive to afferent spontaneous activity manipulations in adults.

Although the mechanisms underpinning the formation of the intrabulbar connections and its relationship with the development of the glomerular map remain to be clarified, it is likely that the coarser link between homologous glomeruli could reflect the coarser glomerular map. The lack of afferent spontaneous activity seems to freeze the system at an early stage, during development and to induce a regression of the already refined connectivity to a coarser status, in adulthood.

In recent papers (L. Ma et al., 2014; Tsai and Barnea, 2014), using different types of transgenic mice, (including the Kir2.1mice) found that the stereotypical pattern of OSN convergence can be restored when the transgene expression is abolished during pregnancy and/or in the early postnatal days, as we observed in our procedure. However, they found that if the map develops abnormally, because the transgene expression is only suppressed after the early days of life, the map continued to be perturbed. It seems that a memory of the disrupted sensory map also is maintained when the transgene expression is later abolished. The mechanisms underlying these results, as well as their relation to the intrabulbar maps, remain to be explained, in a system with such a high degree of plasticity.

Overall, our data indicate that spontaneous afferent activity plays a critical role in the refinement and in the maintenance of the topographic organization of the $\mathrm{OB}$, that in turn, affects odor information processing and olfactory behavior.

\section{References}

Belluscio L, Gold GH, Nemes A, Axel R (1998) Mice deficient in G(olf) are anosmic. Neuron 20:69-81. CrossRef Medline

Belluscio L, Lodovichi C, Feinstein P, Mombaerts P, Katz LC (2002) Odorant receptors instruct functional circuitry in the mouse olfactory bulb. Nature 419:296-300. CrossRef Medline

Bonhoeffer T (1996) Neurotrophins and activity-dependent development of the neocortex. Curr Opin Neurobiol 6:119-126. CrossRef Medline

Bozza TC, Kauer JS (1998) Odorant response properties of convergent olfactory receptor neurons. J Neurosci 18:4560-4569. Medline

Burrone J, O’Byrne M, Murthy VN (2002) Multiple forms of synaptic plasticity triggered by selective suppression of activity in individual neurons. Nature 420:414-418. CrossRef Medline

Caleo M, Lodovichi C, Maffei L (1999) Effects of nerve growth factor on visual cortical plasticity require afferent electrical activity. Eur J Neurosci 11:2979-2984. CrossRef Medline

Clarin T, Sandhu S, Apfelbach R (2010) Odor detection and odor discrimination in subadult and adult rats for two enantiomeric odorants supported by c-fos data. Behav Brain Res 206:229-235. CrossRef Medline

Connelly T, Savigner A, Ma M (2013) Spontaneous and sensory-evoked activity in mouse olfactory sensory neurons with defined odorant receptors. J Neurophysiol 110:55-62. CrossRef Medline

Cossart R, Ikegaya Y, Yuste R (2005) Calcium imaging of cortical networks dynamics. Cell Calcium 37:451-457. CrossRef Medline

Cummings DM, Belluscio L (2010) Continuous neural plasticity in the olfactory intrabulbar circuitry. J Neurosci 30:9172-9180. CrossRef Medline

Danciger E, Mettling C, Vidal M, Morris R, Margolis F (1989) Olfactory marker protein gene: its structure and olfactory neuron-specific expression in transgenic mice. Proc Natl Acad Sci U S A 86:8565-8569. CrossRef Medline

Delay R, Restrepo D (2004) Odorant responses of dual polarity are mediated by cAMP in mouse olfactory sensory neurons. J Neurophysiol 92: 1312-1319. CrossRef Medline

Feinstein P, Bozza T, Rodriguez I, Vassalli A, Mombaerts P (2004) Axon guidance of mouse olfactory sensory neurons by odorant receptors and the beta2 adrenergic receptor. Cell 117:833-846. CrossRef Medline

Feldheim DA, O'Leary DD (2010) Visual map development: bidirectional signaling, bifunctional guidance molecules, and competition. Cold Spring Harb Perspect Biol 2:a001768. CrossRef Medline

Gogos JA, Osborne J, Nemes A, Mendelsohn M, Axel R (2000) Genetic ablation and restoration of the olfactory topographic map. Cell 103:609620. CrossRef Medline

Goldberg JL, Espinosa JS, Xu Y, Davidson N, Kovacs GT, Barres BA (2002) Retinal ganglion cells do not extend axons by default: promotion by neurotrophic signaling and electrical activity. Neuron 33:689-702. CrossRef Medline

Goodman CS, Shatz CJ (1993) Developmental mechanisms that generate precise patterns of neuronal connectivity. Cell 72 [Suppl]:77-98. CrossRef Medline

Grienberger C, Konnerth A (2012) Imaging calcium in neurons. Neuron 73:862-885. CrossRef Medline

Grosmaitre X, Vassalli A, Mombaerts P, Shepherd GM, Ma M (2006) Odorant responses of olfactory sensory neurons expressing the odorant receptor MOR23: a patch clamp analysis in gene-targeted mice. Proc Natl Acad Sci U S A 103:1970-1975. CrossRef Medline

Hallem EA, Carlson JR (2004) The odor coding system of Drosophila. Trends Genet 20:453-459. CrossRef Medline

Hensch TK (2004) Critical period regulation. Annu Rev Neurosci 27:549579. CrossRef Medline

Huberman AD, Feller MB, Chapman B (2008) Mechanisms underlying development of visual maps and receptive fields. Annu Rev Neurosci 31: 479-509. CrossRef Medline

Kerr JN, Greenberg D, Helmchen F (2005) Imaging input and output of neocortical networks in vivo. Proc Natl Acad Sci U S A 102:14063-14068. CrossRef Medline

Kobayakawa K, Kobayakawa R, Matsumoto H, Oka Y, Imai T, Ikawa M, Okabe M, Ikeda T, Itohara S, Kikusui T, Mori K, Sakano H (2007) Innate versus learned odour processing in the mouse olfactory bulb. Nature 450:503-508. CrossRef Medline

Lin DM, Wang F, Lowe G, Gold GH, Axel R, Ngai J, Brunet L (2000) Formation of precise connections in the olfactory bulb occurs in the absence of odorant-evoked neuronal activity. Neuron 26:69-80. CrossRef Medline

Linster C, Johnson BA, Yue E, Morse A, Xu Z, Hingco EE, Choi Y, Choi M, Messiha A, Leon M (2001) Perceptual correlates of neural representations evoked by odorant enantiomers. J Neurosci 21:9837-9843. Medline

Lodovichi C, Belluscio L (2012) Odorant receptors in the formation of the olfactory bulb circuitry. Physiology 27:200-212. CrossRef Medline

Lodovichi C, Belluscio L, Katz LC (2003) Functional topography of connections linking mirror-symmetric maps in the mouse olfactory bulb. Neuron 38:265-276. CrossRef Medline

Lynch JW, Barry PH (1989) Action potentials initiated by single channels opening in a small neuron (rat olfactory receptor). Biophys J 55:755-768. CrossRef Medline

Ma L, Wu Y, Qiu Q, Scheerer H, Moran A, Yu CR (2014) A developmental switch of axon targeting in the continuously regenerating mouse olfactory system. Science 344:194-197. CrossRef Medline

Ma M, Chen WR, Shepherd GM (1999) Electrophysiological characterization of rat and mouse olfactory receptor neurons from an intact epithelial preparation. J Neurosci Methods 92:31-40. CrossRef Medline

Maritan M, Monaco G, Zamparo I, Zaccolo M, Pozzan T, Lodovichi C (2009) Odorant receptors at the growth cone are coupled to localized cAMP and Ca2+ increases. Proc Natl Acad Sci U S A 106:3537-3542. CrossRef Medline

Marks CA, Cheng K, Cummings DM, Belluscio L (2006) Activitydependent plasticity in the olfactory intrabulbar map. J Neurosci 26: 11257-11266. CrossRef Medline

McLaughlin T, Torborg CL, Feller MB, O’Leary DD (2003) Retinotopic map refinement requires spontaneous retinal waves during a brief critical period of development. Neuron 40:1147-1160. CrossRef Medline

McQuiston AR, Katz LC (2001) Electrophysiology of interneurons in the glomerular layer of the rat olfactory bulb. J Neurophysiol 86:1899-1907. Medline

Meister M, Bonhoeffer T (2001) Tuning and topography in an odor map on the rat olfactory bulb. J Neurosci 21:1351-1360. Medline

Mombaerts P (1996) Targeting olfaction. Curr Opin Neurobiol 6:481-486. CrossRef Medline

Mori K, Sakano H (2011) How is the olfactory map formed and interpreted 
in the mammalian brain? Annu Rev Neurosci 34:467-499. CrossRef Medline

Murthy VN (2011) Olfactory maps in the brain. Annu Rev Neurosci 34: 233-258. CrossRef Medline

Nunemaker CS, DeFazio RA, Moenter SM (2003) A targeted extracellular approach for recording long-term firing patterns of excitable cells: a practical guide. Biol Proced Online 5:53-62. CrossRef Medline

Pietrobon M, Zamparo I, Maritan M, Franchi SA, Pozzan T, Lodovichi C (2011) Interplay among cGMP, cAMP, and Ca2 + in living olfactory sensory neurons in vitro and in vivo. J Neurosci 31:8395-8405. CrossRef Medline

Reisert J (2010) Origin of basal activity in mammalian olfactory receptor neurons. J Gen Physiol 136:529-540. CrossRef Medline

Ressler KJ, Sullivan SL, Buck LB (1994) Information coding in the olfactory system: evidence for a stereotyped and highly organized epitope map in the olfactory bulb. Cell 79:1245-1255. CrossRef Medline

Ronnett GV, Parfitt DJ, Hester LD, Snyder SH (1991) Odorant-sensitive adenylate cyclase: rapid, potent activation and desensitization in primary olfactory neuronal cultures. Proc Natl Acad Sci U S A 88:2366-2369. CrossRef Medline

Rospars JP, Lánský P, Duchamp A, Duchamp-Viret P (2003) Relation between stimulus and response in frog olfactory receptor neurons in vivo. Eur J Neurosci 18:1135-1154. CrossRef Medline

Royal SJ, Key B (1999) Development of P2 olfactory glomeruli in P2internal ribosome entry site-tau-LacZ transgenic mice. J Neurosci 19: 9856-9864. Medline

Rubin BD, Katz LC (1999) Optical imaging of odorant representations in the mammalian olfactory bulb. Neuron 23:499-511. CrossRef Medline

Rubin BD, Katz LC (2001) Spatial coding of enantiomers in the rat olfactory bulb. Nat Neurosci 4:355-356. CrossRef Medline

Sakano H (2010) Neural map formation in the mouse olfactory system. Neuron 67:530-542. CrossRef Medline

Savigner A, Duchamp-Viret P, Grosmaitre X, Chaput M, Garcia S, Ma M, Palouzier-Paulignan B (2009) Modulation of spontaneous and odorant-evoked activity of rat olfactory sensory neurons by two anorectic peptides, insulin and leptin. J Neurophysiol 101:2898-2906. CrossRef Medline

Schellinck HM, Forestell CA, LoLordo VM (2001) A simple and reliable test of olfactory learning and memory in mice. Chem Senses 26:663-672. CrossRef Medline

Schoenfeld TA, Marchand JE, Macrides F (1985) Topographic organization of tufted cell axonal projections in the hamster main olfactory bulb: an intrabulbar associational system. J Comp Neurol 235:503-518. CrossRef Medline
Shatz CJ (1996) Emergence of order in visual system development. Proc Natl Acad Sci U S A 93:602-608. CrossRef Medline

Shepherd GM (2004) The synaptic organization of the brain. Oxford: Oxford UP.

Song HJ, Ming GL, Poo MM (1997) cAMP-induced switching in turning direction of nerve growth cones. Nature 388:275-279. CrossRef Medline

Soucy ER, Albeanu DF, Fantana AL, Murthy VN, Meister M (2009) Precision and diversity in an odor map on the olfactory bulb. Nat Neurosci 12:210-220. CrossRef Medline

Spitzer NC (2006) Electrical activity in early neuronal development. Nature 444:707-712. CrossRef Medline

Tan J, Savigner A, Ma M, Luo M (2010) Odor information processing by the olfactory bulb analyzed in gene-targeted mice. Neuron 65:912-926. CrossRef Medline

Thoenen H (1995) Neurotrophins and neuronal plasticity. Science 270: 593-598. CrossRef Medline

Treloar HB, Feinstein P, Mombaerts P, Greer CA (2002) Specificity of glomerular targeting by olfactory sensory axons. J Neurosci 22:2469-2477. Medline

Tsai L, Barnea G (2014) A critical period defined by axon-targeting mechanisms in the murine olfactory bulb. Science 344:197-200. CrossRef Medline

Uchida N, Takahashi YK, Tanifuji M, Mori K (2000) Odor maps in the mammalian olfactory bulb: domain organization and odorant structural features. Nat Neurosci 3:1035-1043. CrossRef Medline

Vassar R, Chao SK, Sitcheran R, Nuñez JM, Vosshall LB, Axel R (1994) Topographic organization of sensory projections to the olfactory bulb. Cell 79:981-991. CrossRef Medline

Yu CR, Power J, Barnea G, O’Donnell S, Brown HE, Osborne J, Axel R, Gogos JA (2004) Spontaneous neural activity is required for the establishment and maintenance of the olfactory sensory map. Neuron 42:553-566. CrossRef Medline

Zhang LI, Poo MM (2001) Electrical activity and development of neural circuits. Nat Neurosci 4 [Suppl]:1207-1214. CrossRef Medline

Zheng C, Feinstein P, Bozza T, Rodriguez I, Mombaerts P (2000) Peripheral olfactory projections are differentially affected in mice deficient in a cyclic nucleotide-gated channel subunit. Neuron 26:81-91. CrossRef Medline

Zheng JQ, Poo MM (2007) Calcium signaling in neuronal motility. Annu Rev Cell Dev Biol 23:375-404. CrossRef Medline

Zou DJ, Feinstein P, Rivers AL, Mathews GA, Kim A, Greer CA, Mombaerts P, Firestein S (2004) Postnatal refinement of peripheral olfactory projections. Science 304:1976-1979. CrossRef Medline 